INVESTIGACIÓN

\title{
Derechos humanos en la Universidad de La Frontera: Un diagnóstico sobre el conocimiento insuficiente de estudiantes de primer año
}

\author{
Human Rights at Universidad de La Frontera: An insufficient knowledge \\ diagnosis in first year students
}

\author{
Leonardo Castillo y Soledad Morales \\ Universidad de La Frontera, Chile
}

\begin{abstract}
RESUMEN Se presentan los resultados del proyecto «Derechos humanos en la Universidad de La Frontera: Un diagnóstico en los estudiantes de primer año», que investiga si los estudiantes que ingresan a primer año en la Universidad de La Frontera poseen conocimientos mínimos en materia de derechos humanos, en específico, aquéllos reconocidos en la Declaración Universal de Derechos Humanos de 1948, y cuál es su apreciación acerca de afirmaciones que relacionan tópicos de derechos humanos con el ejercicio de ciertos derechos políticos. Se parte de la hipótesis de que los estudiantes que egresan de la educación media no cuentan con una formación ciudadana suficiente, particularmente en materia de derechos humanos. Se abordan los cambios en el currículum de formación ciudadana, para posteriormente analizar conceptos de formación cívica, específicamente en derechos humanos. Se analiza la alta abstención electoral a la que contribuye en parte la formación cívica insuficiente. Se presentan y analizan los resultados de la aplicación del instrumento de diagnóstico. Se trata de un estudio cuantitativo y descriptivo, de tipo transversal, cuya muestra fue seleccionada con $95 \%$ de confianza. La recolección de datos se realizó mediante la creación de un instrumento, analizando los resultados mediante el software estadístico SPSS.
\end{abstract}

PALABRAS CLAVE Diagnóstico de percepción, derechos humanos, estudiantes de primer año de universidad, formación cívica, abstención electoral.

ABSTRACT The results of the research project «Human rights at the Universidad de La Frontera: A diagnosis in first year students» are presented, which investigates whether students entering the first year at the Universidad de La Frontera possess minimum knowledge in the field of human rights, specifically those recognized in 1948's Universal Declaration of Human Rights and their appreciation of statements that relate topics 
of human rights to the exercise of certain political rights. It is based on the hypothesis that students who graduate from secondary education do not have sufficient citizenship training, particularly in the area of human rights. It addresses the changes in the curriculum of citizen training, and later, analyzes concepts of civic formation, specifically in human rights. It analyzes the high electoral abstention to which contributes in part the insufficient civic formation. The results of the application of the diagnostic instrument are presented and analyzed. It is a quantitative and descriptive study, of transversal type, whose sample was selected with 95 per cent confidence. Data collection was performed by the creation of an instrument, analyzing the results using SPSS statistical software.

KEYWORDS Perception diagnosis, human rights, first-year college students, citizen education, electoral abstention.

Be informed. Be vigilant! You can't defend your rights if you don't understand them, if you don't know how you got them, and if you don't know who wants to destroy them. Take nothing for granted, for if you do so, you will not take pains to protect your rights. - Faye Wattleton, «An open letter to my daughter». En Life on the line.

\section{Introducción}

Hace más de 240 años, Thomas Jefferson afirmó que todos los hombres son iguales y poseen derechos inalienables, y que para garantizarlos se instituyen gobiernos que derivan sus poderes legítimos del consentimiento de sus gobernados, señalando que aquello constituye una «verdad evidente». Hoy, aquellas premisas de respeto a la democracia y los derechos humanos siguen estando vigentes y son, por cierto, evidentes para todos... ¿ $\mathrm{O}$ no?

La construcción de las democracias modernas y la historia de los derechos humanos (véase Mitoma, 2014) es una cronología de grandes batallas - muchas veces peleadas en conjunto- ${ }^{2}$ y difíciles conquistas. Ambos conceptos se han fraguado en un mismo crisol. Más allá de las posturas respecto a cómo se han de entender las relaciones entre derechos humanos y democracia que señala Robert Alexy (2003: 38), lo cierto es que Derechos Humanos y democracia son conceptos que se encuentran íntimamente ligados. ${ }^{3}$

1. Declaración de Independencia de los Estados Unidos, disponible en http://bit.ly/2jPywoD.

2. Un estudio acabado en Panizza (1995).

3. En su sitio web, Naciones Unidas señala al respecto que «los valores de libertad y respeto por los derechos humanos y el principio de celebrar elecciones periódicas y genuinas mediante el sufragio universal son elementos esenciales de la democracia. A su vez, la democracia proporciona el medio natural para la protección y la realización efectiva de los derechos humanos». «Democracia», Naciones Unidas, disponible en http://bit.ly/2ygL4CS. 
Muñoz, Sánchez y Vásquez señalan citando a Catterberg que «la presencia de actitudes positivas hacia la democracia y los derechos humanos, si bien no es una condición imprescindible para iniciar un sistema político democrático, su existencia es importante para que este sistema se desarrolle y consolide» (Muñoz, Sánchez y Vásquez, 2013: 99). Coincidimos con Erika González (2012) en que los principales agentes de socialización a dicho respecto son la familia, la escuela y los medios de comunicación de masas. Al respecto, en esta investigación nos centraremos en la educación, donde se considera que dichas actitudes positivas es necesario trabajarlas y alimentarlas de contenidos en el contexto escolar.

La presente investigación busca determinar si los estudiantes que ingresan a primer año en la Universidad de La Frontera poseen conocimientos mínimos en materia de derechos humanos, en específico, si conocen aquellos reconocidos en la Declaración Universal de Derechos Humanos de 1948 y cuál es su apreciación acerca de afirmaciones que relacionan tópicos de derechos humanos con el ejercicio de ciertos derechos políticos. Para la realización del estudio, se parte de la hipótesis de que los estudiantes que egresan de la educación media no cuentan con una formación ciudadana suficiente, particularmente en materia de derechos humanos.

En la primera parte, se abordarán los cambios en el currículum de formación ciudadana, para posteriormente, analizar conceptos de formación cívica, específicamente en derechos humanos. En la tercera parte, se analizará la alta abstención electoral como consecuencia - al menos remota- a la que contribuye en parte la formación cívica insuficiente. En la última parte, se presentarán los resultados de la aplicación del instrumento de diagnóstico creado durante la realización de la investigación para diagnosticar los conocimientos sobre derechos humanos de los estudiantes de primer año de la Universidad de La Frontera.

\section{Cambios en el currículum de formación ciudadana}

Contreras y Navia (2013: 438) evidencian que las personas que presentan niveles educacionales más altos participan más, concluyendo que el nivel educacional incidiría positivamente en la participación democrática, de modo que es posible sostener que la entrega de herramientas de formación cívica debiera contribuir a mejorar la participación democrática. Al respecto, Sergio Toro (2008) provee de valiosa evidencia mencionando algunos estudios relevantes que dan cuenta del impacto de la educación cívica sobre la participación, demostrando su efecto positivo. Por su parte, Santisteban y Pagés (2008: 355) también señalan que los estudiantes con más conocimientos cívico-políticos están más abiertos a esta participación.

En Chile, el Programa de Naciones Unidas para el Desarrollo señala que en la actualidad nuestro país «no dispone de una materia específica, en el nivel primario o secundario, en que los alumnos estudien específicamente los derechos y obligaciones 
que tienen como ciudadanos» (PNUD, 2014: 180). Lo anterior, debido a que la asignatura de educación cívica que contemplaba aquellos contenidos dejó de ser obligatoria en la década de los noventa, lo que dio comienzo a una reforma de los currículums educativos que buscaba ampliar el concepto de educación cívica. De manera que, en el currículo prerreforma, la educación cívica y la economía se consideraban como materias independientes para los estudiantes de tercero y cuarto medio, modalidad humanista-científica. Por otra parte, en el currículo postreforma, ellas se incluyen como contenidos abordados en distintos niveles dentro de los subsectores Comprensión del Medio Natural, Social y Cultural — primero a cuarto básico-, Estudio y Comprensión de la Sociedad — quinto a octavo básico- y del sector Historia y Ciencias Sociales - primero a cuarto medio-, además de incluir a la formación ciudadana como objetivo transversal. Así las cosas, el norte formativo se formuló, en términos de Cristian Cox, como «un conjunto de habilidades y actitudes relacionadas con la democracia y los derechos fundamentales» (Cox, 2011: 19), transitando desde un esquema en que la educación cívica se concentraba en una asignatura en la educación media centrada en conocimientos sobre la estructura y funcionamiento del sistema de gobierno, a una formación ciudadana que además, incluyera «habilidades, valores y actitudes fundamentales para la vida en democracia». El nuevo currículo, como prosigue Cox, plantea contenidos y habilidades de formación ciudadana a lo largo de toda la secuencia escolar y no limitada al área de la Historia y Ciencias Sociales, sino también a Lengua Castellana y Comunicación, Orientación, Filosofía y en los objetivos fundamentales transversales. ${ }^{4} \mathrm{Al}$ respecto, como señala Gonzalo Fonseca en una edición anterior de esta misma revista, «queda la sensación que el marco curricular de la Educación Media chilena constituye un documento amplio, general y un tanto ambicioso, en donde la transversalidad de ciertos objetivos hace asumir la responsabilidad de todos y nadie al mismo tiempo» (Fonseca, 2015: 67).

Respecto del grado de conocimiento efectivo que presentan los estudiantes chilenos en educación cívica y formación ciudadana, el Primer Informe Nacional de Resultados del ICCS (2010) reveló que los estudiantes chilenos de octavo básico se encuentran bajo el promedio los estudiantes de los países participantes, pero sobre los países latinoamericanos. Además, «los que más han aprendido son, en general, los

4. En términos del PNUD: «Desde entonces, la educación cívica no se relaciona exclusivamente con asignaturas específicas en un nivel de enseñanza, sino que, desde primero básico a cuarto medio, aparece ligada al cumplimiento de objetivos relacionados con derechos, deberes y competencias ciudadanas, pertenecientes a diversas asignaturas, dentro de cuyos contenidos se incorporaron temáticas sobre formación cívica, tales como, Lenguaje y Comunicación, Orientación, Filosofía e Historia. Se incorporaron diversos contenidos de formación cívica a los objetivos fundamentales transversales que hacen referencia a las finalidades generales de la educación, esto es, «a los conocimientos, habilidades, actitudes, valores y comportamientos que se espera que los estudiantes desarrollen en el plano personal, intelectual, moral y social»» (PNUD, 2014: 180). 
que viven y estudian en condiciones socioeconómicas más aventajadas, es decir, esta forma de conocimiento también es entregada de manera poco equitativa a los estudiantes en nuestro país» (IEA, 2009: 36). Relacionando las conclusiones de Contreras y Navia con las de este informe, se aprecia que quienes se encuentran en condiciones socioeconómicas más aventajadas aprenden más y, al mismo tiempo, participan más. No se puede señalar que una de las variables sea dependiente de la otra, o una de las situaciones consecuencia directa de la otra, pero sí parece necesario considerar estos efectos para el presente estudio.

De otra parte, un reciente estudio del 2016, titulado «Formación ciudadana en el sistema escolar chileno: Una mirada a las prácticas actuales y recomendaciones de mejora» de la Agencia de Calidad de la Educación (2016: 7-26) concluye que existe poco conocimiento acerca del modo en que las escuelas están incorporando este ámbito formativo en sus aulas; en tanto, el trabajo de formación ciudadana se concentra fuertemente en la asignatura de Historia, Geografía y Ciencias Sociales - sobre cuyos profesores recae principalmente esta responsabilidad-, con alta variabilidad en el grado de profundidad, grandes diferencias entre las escuelas respecto a los contenidos trabajados y una pobre preparación del profesorado en formación ciudadana. Como señalan Muñoz, Sánchez y Vásquez (2013), existe una distancia entre el currículum formulado y el implementado por los profesores en las salas de clases. En otro estudio, formulado por Reyes y otros (2013), referido a cómo comprenden los profesores la formación ciudadana desde su ejercicio profesional y cómo la trabajan en sus clases, concluyen, entre otras cosas, que al momento de planificar sus clases, los docentes se basan más en su experiencia de ejercicio ciudadano antes que en la formación académica recibida en la universidad (Reyes y otros, 2013: 234). De esta manera, siendo heterogéneas las experiencias, es factible que también lo sean los resultados. Así las cosas, parece ser que aún estamos muy distantes de estadios de mayor desarrollo o sofisticación como «la educación para la ciudadanía global o educación para el desarrollo» que ya preocupa a gobiernos e investigadores en otras latitudes (véase Boni y otros, 2012).

Respecto de la normativa que rige estos currículums en nuestro país, la Ley 20.911, que «Crea un plan de formación ciudadana para los establecimientos educacionales reconocidos por el Estado», publicada en el Diario Oficial en abril de 2016 y presentada por mensaje en marzo de 2015, señala entre sus fundamentos ${ }^{5}$ que «la educación cívica juega un rol clave en el fortalecimiento de las democracias». Del mismo modo, y citando los fundamentos del Primer Informe Nacional de Resultados, «la evidencia es clara en mostrar que nuestro país tiene un trecho importante por avanzar en la calidad de su formación ciudadana». Hay señales interesantes en este mensaje: por

5. Más información sobre la historia de esta ley en la Biblioteca del Congreso Nacional de Chile, disponible en http://bit.ly/2yh3Slp. 
una parte, se reconoce la necesidad de hacer cambios, al parecer motivados por la obtención de resultados que pudieren haber sido considerados subóptimos por el gobierno que presenta la iniciativa, y por otro, una coherencia discursiva en cuanto a que los desafíos que ha asumido el Estado en materia de educación han ido primero enfocados en la cobertura, ${ }^{6}$ para posteriormente asumir los desafíos respecto de la calidad. ${ }^{7}$ Respecto de esta última, sólo mencionar que para Blanco Guijarro la educación de calidad para todos debe comenzar en la primera infancia y las cualidades que esta educación debe reunir, para ser efectivamente de calidad, son: relevancia, pertinencia, equidad, eficacia y eficiencia, además de ser inclusiva.

Pero a su vez, el derecho a la educación requiere hacer efectivos otros derechos como el de la salud, la nutrición, o el derecho de los niños a no trabajar. La indivisibilidad e interdependencia de los derechos exige el desarrollo de políticas «intersectoriales» y mecanismos de coordinación interinstitucional que permitan el ejercicio integral de todos los derechos humanos (Blanco, 2008: 33).

Así, no se puede entender la calidad sin considerar los tópicos que se relevan en esta investigación.

Como señalan las investigadoras de las Universidades de Navarra y Oxford, Ugarte, Repáraz y Naval, «la escasa participación política es un problema social de origen educativo. En este sentido, familia y escuela proporcionan los conocimientos, actitudes y habilidades necesarias para participar en sociedad» (Ugarte, Repáraz y Naval, 2013: 224). Consideramos que esta reflexión es totalmente extrapolable a nuestra realidad. Así, desde el contexto educativo, la responsabilidad en la formación ciudadana se ha de encontrar presente en todas las etapas de la educación, esto es, desde la preescolar a la educación superior.

Sin perjuicio de esto último, y siendo un hecho irrefutable que no todos los estudiantes que egresan de la educación secundaria llegan a la educación universitaria o técnica profesional, es que se torna necesario que se alcancen estándares mínimos en la educación obligatoria respecto de aquella formación ciudadana que contemple el respeto $-\mathrm{y}$ para ello el conocimiento- acerca de los derechos humanos y de la democracia.

\section{Educación en derechos humanos, una deuda pendiente}

Como señala Pedro Leiva, «la construcción de una sociedad caracterizada por una convivencia democrática se encuentra indiscutiblemente ligada al fomento del res-

6. Sobre la expansión y acceso a la educación superior, véase Leihy y Salazar (2017).

7. En una arquitectura que, como señalan Oliva y Gascón (2016: 313), hace símil la calidad de la educación con la estandarización fundada en la medición. 
peto de los derechos humanos y la educación para la paz mundial» (Leiva, 1999: 94). Si buscásemos una definición de los objetivos generales de la educación en derechos humanos, probablemente se acercaría a la referida por la ministra de Educación de España en la Comisión de Educación y Ciencia del Congreso de los Diputados, celebrada en septiembre de 2006 y referida por Rafael Valencia: «Con la asignatura de Educación para la Ciudadanía y los Derechos Humanos queremos que nuestros alumnos adquieran los conocimientos necesarios para reflexionar y actuar como ciudadanos responsables en el ámbito público» (Valencia, 2010: 75). En dicho sentido, es fundamental el analizar la educación en derechos humanos, dados sus impactos positivos en los estudiantes cuanto ciudadanos en formación. Entre estos impactos se encuentran, de acuerdo a Amnistía Internacional, el «abordar las causas subyacentes a las violaciones de derechos humanos, prevenir los abusos contra esos derechos, luchar contra la discriminación, promover la igualdad y aumentar la participación de las personas en los procesos democráticos de toma de decisiones». ${ }^{8}$ Para el logro de aquéllo se requiere que los ciudadanos se encuentren debidamente informados, cuenten con los conocimientos, valores que les permitan desarrollar la conciencia de la responsabilidad común que se tiene para con los demás y para consigo respecto a la defensa de los derechos humanos.

La educación en materia de derechos humanos no sólo constituye una parte integral del derecho a la educación, sino que ha ido obteniendo cada vez mayor reconocimiento como derecho humano en sí mismo (véase Blengio, 2013; Richard, 2005; Emmert, 2011). Ello se ve reforzado al reconocerse el deber del Estado de velar por la garantía del derecho a la educación como derecho fundamental (PNUD, 2014: 171). ${ }^{9}$

De acuerdo al Programa de Naciones Unidas para el Desarrollo, se considera a la educación un indicador clave del desarrollo, tanto de los países como de las personas que habitan en él, afirmando este organismo que «la educación es un factor fundamental de las competencias que permiten a los individuos insertarse en el mundo laboral y la sociedad de forma exitosa» (PNUD, 2014: 171). A ello se suma que «en Chile la educación tradicionalmente se ha reconocido como un instrumento de movilidad social y un camino para la superación de la pobreza y la desigualdad» (PNUD, 2014: 171). En ese orden de cosas, Nicolás Espejo puntualiza que «el derecho a la educación se erige como el derecho movilizador por excelencia de las políticas orientadas hacia

8. «Educación en derechos humanos», Amnistía Internacional, disponible en http://bit.ly/2AuGhnd.

9. Sobre el derecho a la educación superior, una discusión interesante es la que plantea el profesor de la UCL Tristan McCowan: respecto a la pregunta de si existe un derecho universal a la educación superior: i) la educación superior es un derecho de todas las personas, pero sólo como una de las diversas experiencias educativas disponibles para los adultos; ii) los procedimientos de acceso no discriminatorios son importantes, pero no adecuados en sí mismos; deben estar disponibles para todos aquéllos que deseen estudiar y con un nivel mínimo de preparación (McCowan, 2012). 
la cohesión social, la igualdad y la libertad» (Espejo, 2014: 22). Ello permite colegir que garantizar el derecho a la educación propende a fortalecer la democracia, ya que, al conocer sus derechos, los ciudadanos tienen mayor probabilidad de ejercerlos eficazmente. Por lo tanto, no da lo mismo consagrar el derecho a la educación que simplemente garantizar su acceso. Al respecto, se requiere un rol activo de parte del Estado, donde, como señalan Eric Palma y Antonia Santos, «la pobreza no puede ser una excusa para la inacción» (Palma y Santos, 2015: 252).

En materia internacional, la Declaración Universal de Derechos Humanos (1948), en su artículo 26.2, luego de señalar que «toda persona tiene derecho a la educación», establece que

la educación tendrá por objeto el pleno desarrollo de la personalidad humana y el fortalecimiento del respeto a los derechos humanos y a las libertades fundamentales. Promoverá la comprensión, la tolerancia y la amistad entre todas las naciones y todos los grupos raciales o religiosos). ${ }^{10}$

De esta forma, transcurridas las acciones relativas a asegurar garantías mínimas, como el acceso universal, la obligatoriedad y la gratuidad, y dado el carácter de progresivos de los derechos humanos a partir de 1968, la Organización de Naciones Unidas ha celebrado conferencias gubernamentales mundiales, dedicadas a evaluar el progreso de los derechos consagrados en la Declaración. Así, en la Conferencia de 1993 realizada en Viena, 171 países, incluido Chile, aprobaron la Declaración y el Programa de Acción de Viena, que contiene una planificación para fortalecer la aplicación de los derechos humanos, destacándose en su texto la relación entre democracia, desarrollo y promoción de estos derechos. En el parágrafo 33, sección i de esta declaración, se consagra que

los derechos a la educación, la capacitación y la información pública en materia de derechos humanos son indispensables para establecer y promover relaciones estables y armoniosas entre las comunidades, así como para fomentar y consolidar la comprensión mutua, la tolerancia y la paz.

Además, se instó a los Estados para que incluyeran la temática de los «derechos humanos, derecho humanitario, democracia y Estado de derecho, como materias de los programas de estudio de toda institución educativa». ${ }^{11}$ A partir de esta Declaración y de acuerdo a la sugerencia de la Conferencia Mundial, la Asamblea General de

10. «Declaración Universal de los Derechos Humanos», Naciones Unidas, disponible en http://bit. ly/2AwBaDa.

11. «Decenio de las Naciones Unidas para la educación en la esfera de los derechos humanos», Oficina del Alto Comisionado de las Naciones Unidas para los Derechos Humanos, disponible en http://bit. ly/2ygK550. 
las Naciones Unidas, en la resolución 49/184 del 23 de diciembre de 1994, anunció el establecimiento del «Decenio de las Naciones Unidas para la educación en la esfera de los derechos humanos» por el período de diez años contados a partir del 1 de enero de 1995, a partir del cual las acciones de la Organización de Naciones Unidas han ido en directa relación con establecer la educación en derechos humanos en la educación mundial, por cuanto el 10 de diciembre de 2004, la Asamblea General proclamó por la resolución 59/113, el Programa Mundial para la Educación en Derechos Humanos, cuyo objetivo consiste en promover la aplicación de programas, en todos los sectores, sumando que el 23 de marzo de 2011, el Consejo de Derechos Humanos, aprobó la «Declaración de las Naciones Unidas sobre educación y formación en materia de derechos humanos». ${ }^{12}$

Chile, como Estado miembro de Naciones Unidas, debe guiarse por estas declaraciones y conferencias que profundizan los derechos consagrados en la Declaración Universal y en las normas fundamentales de los Estados, de modo que aquéllas sirven como pautas respecto del contenido e implementación de políticas públicas, planes y programas en materia educativa, los que debiesen adecuar sus contenidos a estas pautas que establecen la educación en derechos humanos como una materia fundamental, respaldados por la legislación nacional y los instrumentos internacionales emanados desde Naciones Unidas, instituyendo como una prioridad la educación en materia de derechos humanos. En este sentido, de acuerdo al Programa de Naciones Unidas para el Desarrollo, todos estos compromisos internacionales a través de los años han llevado a Chile a reconocer el derecho a la educación, incluso a nivel constitucional, jugando el Estado un rol preponderante en su garantía y teniendo como principal preocupación el acceso a la enseñanza, de modo que los estándares exigidos internacionalmente, suponen que el Estado debe garantizar:

La educación primaria universal y la educación secundaria generalizada, independientemente de las capacidades y aptitudes de los alumnos. Se entiende que una educación primaria y secundaria de calidad son las llaves que permiten al estudiante que lo desee avanzar a niveles superiores de educación (PNUD, 2014: 172).

En el contexto nacional, los tratados y acuerdos internacionales ratificados por nuestro país, y que se han generado en torno al derecho a la educación como derecho humano consagrado en el artículo 26 de la Declaración Universal de Derechos Humanos, tales como el Pacto Internacional de Derechos Económicos, Sociales y Culturales en su artículo 13, la Convención de los Derechos del Niño en sus artículos 28 y 29 y la Convención sobre Lucha Contra las Discriminaciones en las Esferas de la Enseñanza en sus artículos 4 y 5 , generan obligaciones expresas para los Estados parte

12. «Decenio de las Naciones Unidas para la educación en la esfera de los derechos humanos», Oficina del Alto Comisionado de las Naciones Unidas para los Derechos Humanos. 
en materia de educación, lo que es particularmente importante en el contexto chileno, en tanto que, de acuerdo con lo establecido por el artículo 5 de la Constitución Política de la República de 1980, los tratados internacionales ratificados por Chile forman parte integrante de la legislación chilena, y si bien se discute la jerarquía con la que ingresan, ${ }^{13}$ es indiscutible su incorporación al ordenamiento jurídico chileno. Así, en Chile, en materia de educación, la Constitución Política de la República, norma fundamental de nuestra institucionalidad, consagra en el capítulo 3, bajo el acápite «De los derechos y deberes constitucionales», su artículo 19, que señala que: «La Constitución asegura a todas las personas: 10) el derecho a la educación», agregando que «la educación tiene por objeto el pleno desarrollo de la persona en las distintas etapas de su vida».

Para el profesor Nogueira (2008; véase también Latapí, 2009):

La educación debe orientarse hacia el pleno desarrollo de la personalidad humana y del sentido de su dignidad, y debe fortalecer el respeto por los derechos humanos y las libertades fundamentales; debe capacitar a todas las personas para participar efectivamente en una sociedad libre, favorecer la comprensión, la tolerancia y la amistad entre todas las naciones y entre todos los grupos raciales, étnicos o religiosos, y promover las actividades de las Naciones Unidas en pro del mantenimiento de la paz. Asimismo, la educación debe favorecer la igualdad entre los sexos y el respeto del medio ambiente (Nogueira, 2008: 221).

Por su parte, esta normativa constitucional determina el contenido de una Ley Orgánica Constitucional, la Ley 20.370 que Establece la Ley General de Educación, publicada en el Diario Oficial en septiembre de 2009, en la cual se contienen los principios y directrices en materia de educación, y que define a la educación en el artículo 2 señalando:

La educación es el proceso de aprendizaje permanente que abarca las distintas etapas de la vida de las personas y que tiene como finalidad alcanzar su desarrollo espiritual, ético, moral, afectivo, intelectual, artístico y físico, mediante la transmisión y el cultivo de valores, conocimientos y destrezas. Se enmarca en el respeto y valoración de los derechos humanos y de las libertades fundamentales, de la diversidad multicultural y de la paz, y de nuestra identidad nacional, capacitando a las personas para conducir su vida en forma plena, para convivir y participar en forma respon-

13. Respecto de los tratados internacionales relativos a los derechos fundamentales, si bien existe certeza en el ordenamiento jurídico chileno de que constituyen una limitación al ejercicio de la soberanía, de acuerdo a lo establecido en el artículo 5 inciso 2 de la Constitución Política de la República, es un tema debatido cuál es su jerarquía. Al respecto, en la doctrina constitucional se plantean las siguientes posiciones doctrinarias: a) jerarquía supraconstitucional; b) jerarquía supralegal pero infraconstitucional (este es el criterio aplicado por el Tribunal Constitucional Chileno desde el año 2002 en algunas sentencias); c) jerarquía constitucional y d) rango legal de los tratados internacionales. 
sable, tolerante, solidaria, democrática y activa en la comunidad, y para trabajar y contribuir al desarrollo del país.

A partir de esto, el artículo 5 señala que

corresponderá al Estado, asimismo, fomentar la probidad, el desarrollo de la educación en todos los niveles y modalidades y promover el estudio y conocimiento de los derechos esenciales que emanan de la naturaleza humana; fomentar una cultura de la paz y de la no discriminación arbitraria; estimular la investigación científica, tecnológica y la innovación, la creación artística, la práctica del deporte, la protección y conservación del patrimonio cultural y medio ambiental, y la diversidad cultural de la nación.

Por último, el artículo 30 se refiere a que «la educación media tendrá como objetivos generales, sin que esto implique que cada objetivo sea necesariamente una asignatura, que los educandos desarrollen los conocimientos, habilidades y actitudes que les permitan», agregando en el número 1, «en el ámbito personal y social», continuando señalando en la letra d),

conocer y apreciar los fundamentos de la vida democrática y sus instituciones, los derechos humanos y valorar la participación ciudadana activa, solidaria y responsable, con conciencia de sus deberes y derechos, y respeto por la diversidad de ideas, formas de vida e intereses.

De esta manera, los estudiantes, al terminar la educación media, debieran ser capaces de cumplir con lo establecido en esta norma conociendo los principales fundamentos e instituciones de la democracia, comprender en qué consisten los derechos humanos en un Estado democrático y relacionarse con la participación ciudadana y sus elementos. Todo ello considerando, además, que la gran mayoría de los estudiantes que ingresan a la universidad son ciudadanos con derecho a voto y, por esto, participantes activos del sistema electoral y de la vida democrática, de acuerdo a Ley 20.568, ${ }^{14}$ que Regula la Inscripción Automática, Modifica el Servicio Electoral y Moderniza el Sistema de Votaciones, publicada en el Diario Oficial en enero de 2012, debieran tener los conocimientos mínimos para poder involucrarse en la vida política como ciudadanos, lo que se intentó medir durante el desarrollo de la presente investigación.

14. Desde el 31 de enero de 2012 comenzó a regir la Ley 20.568, que regula la inscripción automática y el voto voluntario, con lo cual quedan inscritas automáticamente en el registro electoral todas las personas que cumplan los requisitos para votar. 


\section{«Ni ahí» con las elecciones: Alta abstención electoral de los jóvenes, consecuencia mediata de las carencias en la formación cívica}

No se sugiere, por cierto, que la participación política se agote en las elecciones. Al respecto y para el caso chileno, la investigadora Salomé Morales (2015) concluye que pese a los altos niveles de abstención electoral, los jóvenes chilenos están interesados en la política y «participan en la misma de muy diversas formas». ${ }^{15}$ Sin perjuicio, se coincide con Dieter Nohlen (2004) en que la participación electoral es la más importante por ser la más democrática e igualitaria, el más central de los canales de vinculación del electorado y de sus preferencias políticas con el poder y, finalmente, porque a través de ella toda la sociedad se vincula o está afectada de forma vinculante por el resultado: la legislación y el desarrollo económico y social como producto de las políticas llevadas a cabo por los gobernantes.

Desde el retorno a la democracia, la participación electoral ${ }^{16}$ ha tenido una tendencia al decrecimiento. Considerando las elecciones presidenciales, la participación electoral se ha comportado de la siguiente manera: $94,7 \%$ en $1989 ; 90,5 \%$ en 1993 ; 90,6\% en 1999; 90,6\% en 2000; 83,9\% en 2005; 87,1\% 2006; 86,9\% 2010; $42 \% 2013$. Respecto a los resultados de la última elección presidencial —en la cual se estrenó el sistema de inscripción automática y voto voluntario—, ${ }^{17}$ cabe destacar que el $58 \%$ del padrón electoral se abstuvo de participar. ${ }^{18} \mathrm{Al}$ respecto, el Instituto Internacional para la Democracia y la Asistencia Electoral (IDEA) sostiene que Chile sería el país que presenta la mayor abstención electoral a nivel global. ${ }^{19}$

Las causas del abstencionismo electoral pueden ser múltiples ${ }^{20} \mathrm{y}$ afectan no solo a los jóvenes. No obstante, parece ser en aquel segmento etario donde el impacto es más notorio, indicando Parker que

en general, existe una percepción juvenil, en todos los estratos, de que la actividad política y los partidos constituyen una realidad diferenciada que está aparte y alejada de la vida cotidiana, los intereses y las preocupaciones de la mayoría de la gente y en especial de los jóvenes (Parker, 2003: 15; véase también Haime, 2017).

No obstante lo anterior, es necesario explicitar que el impacto de la abstención

15. Respecto del impacto que tienen las redes multidireccionales, como lo son las redes sociales, en la participación electoral, véase Navia y Ulriksen (2017).

16. Respecto a la participación, véase Morales (2016a: 57-126).

17. Ley 20.568 de 2012.

18. Datos obtenidos del Instituto Internacional para la Democracia y la Asistencia Electoral (IDEA), disponible en http://bit.ly/2ygTLxo.

19. «Infobae: Chile es el país con mayor abstención electoral del mundo», La Tercera, 16 de mayo de 2015, disponible en http://bit.ly/2ygB9Nm.

20. Un estudio interesante es el que plantea Vilajosana (2009). 
no afecta de manera similar a todos los estratos socioeconómicos, en tanto el mismo Parker (2003: 9) señalaba en un estudio del año 2003 que existía una mayor cantidad de inscritos en el nivel socioeconómico alto que en el medio y bajo (39\% contra $30,4 \%$ en el nivel medio y $31,3 \%$ en el nivel socioeconómico bajo). Al respecto, Contreras y Navia más recientemente refrendan esa tendencia indicando que

respecto a las elecciones de 2009, en Maipú, la comuna más poblada del país, sólo el 30,3\% de la población en edad de votar estaba inscrita. En Vitacura, la comuna con más altos ingresos, la tasa de inscripción alcanzaba al 97,3\% de la población en edad de votar. En 2010 la tasa de inscripción en comunas de altos ingresos como Providencia y Las Condes era de 97,1 y 69,9\%, respectivamente, mientras que en la populosa comuna de clase media baja de Puente Alto alcanzaba a $29 \%$ (Contreras y Navia, 2013: 420).

A esto debe agregarse que en el nuevo sistema de inscripción automática y voto voluntario, nada indica que estas cifras vayan a revertirse.

Tomás Chuaqui (2007: 183: 204) señala como elementos que pudieran incidir en el aumento de la participación electoral el mejorar la educación cívica, transparentar las decisiones y la información política, regular las encuestas de opinión pública, aumentar la «calidad» del debate público e incrementar la competitividad de las elecciones. Así, la presente investigación se enfocará sobre el primero de estos elementos, sin desconocer la importancia de los demás, así como las vinculaciones existentes entre todos ellos.

\section{La investigación}

El presente estudio se llevó a cabo utilizando una metodología cuantitativa, descriptiva, de tipo transversal; la muestra que se utilizó para realizarla fue seleccionada con $95 \%$ de confianza. Para recolectar los datos, se creó un instrumento consistente en una encuesta que fue aplicada a los estudiantes que ingresaron a primer año en el año académico 2015 en la Universidad de La Frontera, cuyos resultados obtenidos fueron analizados a través del software estadístico SPSS.

Como se ha señalado, el objetivo de la investigación ha consistido en realizar un diagnóstico en los estudiantes de primer año de la Universidad de La Frontera, con el fin de identificar si poseen conocimientos mínimos en materia de derechos humanos, en específico, si conocen aquellos derechos humanos reconocidos en la Declaración Universal de Derechos Humanos de 1948, catálogo de derechos que parecieran ser menos discutibles —o si se quiere, más «evidentes»-, y su apreciación acerca de afirmaciones que relacionan tópicos de derechos humanos con el ejercicio de los derechos políticos.

Al iniciar el trabajo, la percepción consistió en que al eliminarse la asignatura de Educación Cívica para la educación media, los estudiantes que egresan de este nivel 
de enseñanza no han adquirido de manera suficiente los conocimientos mínimos que plantea el objetivo general en esta materia. Por conocimientos mínimos, se hace referencia a la identificación de los derechos humanos reconocidos en la Declaración Universal de Derechos Humanos de 1948, así como la apreciación acerca de afirmaciones que relacionan tópicos de derechos humanos con el ejercicio de derechos políticos que requieren precisamente la comprensión de los conceptos mínimos referidos.

De esta manera, la hipótesis de trabajo consistió en que los estudiantes de primer año poseen escasos conocimientos sobre los derechos humanos. Lo anterior, puesto que las asignaturas de Consejo de Curso y Orientación e Historia, Heografía y Ciencias sociales, que son aquéllas más cercanas a estas temáticas —esto es, donde ellas deberían revisarse-, no tienen este objetivo como norte, por lo que en la práctica muchas veces se privilegia el logro de otros objetivos y resultados de aprendizaje, igualmente importantes, centrándose en los contenidos específicos de cada asignatura, sin aportar a los objetivos transversales que deben lograrse en general, donde se encuentran la educación y el conocimiento en derechos humanos. Por su parte, existe la misma percepción respecto a la educación universitaria, esto es, que centra su labor en los contenidos específicos de cada carrera, sin otorgarles una trascendencia o enfoque de derechos humanos, además de realizar nivelación a los estudiantes en otras materias, mayormente relacionadas con las carreras que se imparten, y no en materias de derechos humanos.

Al desconocerse la veracidad de estas observaciones y la real situación de la educación en derechos humanos en los conocimientos de los estudiantes de primer año, es que no ha sido posible afrontar la temática mediante propuestas y acciones remediales. Todo esto, cumpliendo con la labor que debiese realizar una universidad pública, en orden a formar profesionales y ciudadanos que sepan desenvolverse en una sociedad democrática. Tal como lo señala el documento «Política de formación profesional y aseguramiento de la calidad», elaborado por la Dirección Académica de Pregrado (hoy Vicerrectoría) y la Dirección de Análisis y Desarrollo Institucional de la Universidad de La Frontera, la estructura del currículo debe «garantizar el desarrollo de competencias genéricas y la formación integral de los estudiantes», formación integral que, sin duda, debiese incluir la temática de los derechos humanos.

Así, la presente investigación tuvo como objetivo general analizar el conocimiento de los estudiantes de primer año de la Universidad de La Frontera respecto a la temática de los derechos humanos, de lo cual se derivaron tres objetivos específicos: a) identificar los elementos que entrega la Universidad de La Frontera en torno al desarrollo de la temática de los derechos humanos; b) creación de un instrumento que permitiera diagnosticar, en esta materia, el conocimiento y la percepción que poseen los estudiantes de primer año de la Universidad de La Frontera; y c) proponer acciones remediales que debiera realizar la universidad para abordar los déficits que se identifiquen. 


\section{Presentación de resultados}

En cuanto a la caracterización de los estudiantes que ingresaron el año académico 2015 a primer año en la universidad, el anuario estadístico de la Universidad de La Frontera ${ }^{21}$ señala que el año 2015 ingresaron 2.209 estudiantes, de los cuales el 55\% son de sexo masculino y $45 \%$ de sexo femenino. En cuanto al régimen educacional de proveniencia, el $30 \%$ provenía de un establecimiento municipal, $62 \%$ de un colegio particular subvencionado y $5 \%$ de un colegio particular pagado. El $80 \%$ son provenientes de la región de La Araucanía. Respecto al quintil socioeconómico al que pertenecían, el $24 \%$ pertenecía al primer quintil, el $23 \%$ al segundo quintil, el $18 \%$ al tercer quintil, el $14 \%$ al cuarto quintil y solo el $5 \%$ al quinto quintil. Finalmente, del total de estudiantes, el $22 \%$ declara tener ascendencia mapuche.

El instrumento aplicado fue contestado por 327 estudiantes de primer año, cuyas edades fluctuaban entre los 18 y 35 años, obteniéndose una media de 19,6 años respecto de los estudiantes encuestados, donde el $58 \%$ corresponde a hombres y $42 \%$ a mujeres, cifra cercana a la caracterización realizada por la Dirección de Análisis para ese año académico, tal como se muestra en la figura 1.

El instrumento se aplicó en las seis facultades de la universidad, ${ }^{22}$ donde el porcentaje de encuestados se condice con el número de estudiantes que pertenecen a cada una de ellas, con un mayor número en la Facultad de Ingeniería y Ciencias y el número menor en la Facultad de Odontología, la más grande y pequeña en cuanto al número de estudiantes respectivamente, tal como se muestra en la figura 2.

Tomando en cuenta que la región de La Araucanía presentó la proporción más alta de personas pertenecientes al pueblo mapuche, ${ }^{23}$ se consideró pertinente incluir la pregunta: «¿Te reconoces perteneciente a un pueblo originario?». El 22,7\% de los estudiantes respondió de manera afirmativa, lo que coincide con la caracterización que la universidad realizó para el año académico 2015, tal como se muestra en las figura 3 y 4 .

En la pregunta 8 se consultó a los estudiantes su apreciación en cuanto al nivel de conocimiento respecto de derechos humanos establecidos en la Declaración Universal de Derechos Humanos de 1948, derechos que parecieran ser más «evidentes» para los estudiantes que recién inician su vida universitaria. Las opciones que tenían los estudiantes para contestar correspondían a «muy bueno», «bueno», «regular», «poco» $\mathrm{y}$ «muy poco». Los resultados se presentan en la tabla 1.

21. Universidad de La Frontera, Dirección de Análisis Institucional, Anuario 2015, disponible en http:// bit.ly/2AtFXVL.

22. Medicina, Odontología; Ingeniería y Ciencias; Educación, Ciencias Sociales y Humanidades; Ciencias Agropecuarias y Forestales, y Ciencias Jurídicas y Empresariales.

23. De acuerdo a la encuesta de caracterización socioeconómica nacional (Casen) del año 2013, un número de 1.565.915 personas se consideran indígenas, de los cuales 309.952 viven en la región de La Araucanía. 


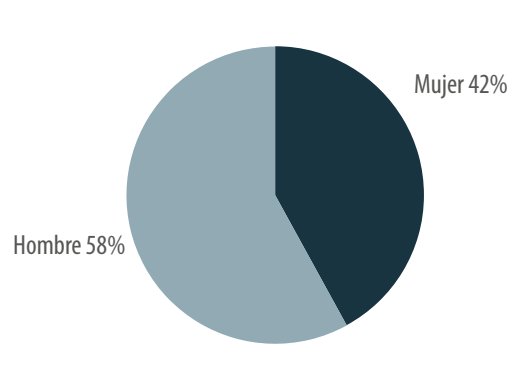

Figura 1. Identificación de la muestra.

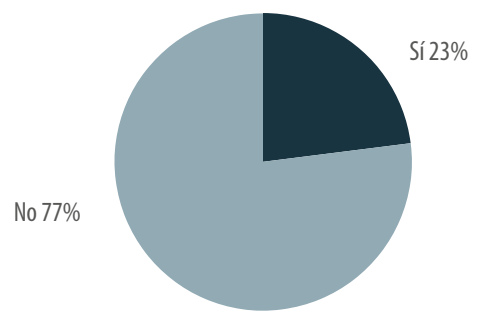

Figura 3. ¿Te reconoces perteneciente a un pueblo originario?

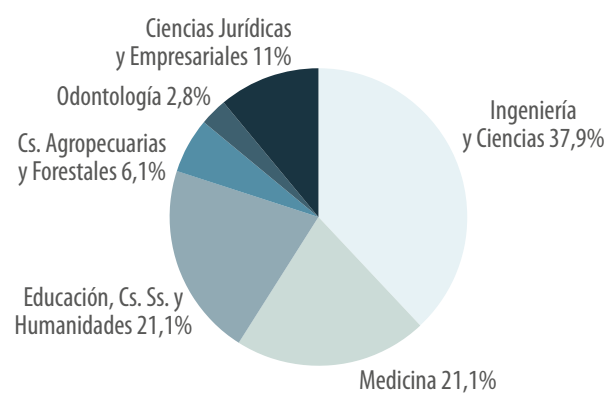

Figura 2. Porcentaje de encuestados según facultad.

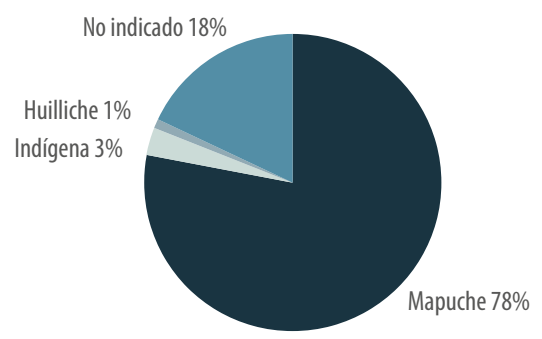

Figura 4. $i$ Te reconoces perteneciente a un pueblo originario? ¿Cuál?

Como apreciación general, si bien existen particularidades respecto al conocimiento de los derechos en específico, los cuales se analizan más adelante, la gran mayoría de los estudiantes califica su nivel de conocimiento respecto de los derechos consultados entre las categorías intermedias «bueno», «regular» $\mathrm{y}$ «poco».

En los extremos, el porcentaje de estudiantes que califican su nivel de conocimiento como «muy poco» es minoritario. Sólo sobrepasan escasamente los dos dígitos en relación a los derechos de "protección de la ley ante injerencias o ataques arbitrarios a la vida privada, honra y reputación», con el 13\%; "presunción de inocencia y recurso efectivo ante los tribunales nacionales», con el 15\%; «ser oído públicamente con justicia por tribunales independientes e imparciales», con el $11 \%$, $y$ «derecho de propiedad», con el $10 \%$.

En el otro extremo, el porcentaje de quienes califican su nivel de conocimiento como «muy bueno», también por regla general es minoritario, con excepciones como la «prohibición de la esclavitud, servidumbre y trata de esclavos y prohibición de torturas, tratos crueles inhumanos y degradantes», con el 19\%; «derecho a la nacionalidad», con el $23 \%$; «derecho a casarse y formar familia», con el $22 \%$, y «libertad de pensamiento, conciencia y religión y libertad de opinión y expresión», con el $26 \%$. 
Tabla 1. Nivel de conocimiento sobre derechos humanos

\begin{tabular}{|c|c|c|c|c|c|}
\hline & Muy bueno & Bueno & Regular & Poco & Muy poco \\
\hline $\begin{array}{l}\text { Derecho a la vida, libertad, seguridad e igualdad en dignidad } \\
\text { y derechos }\end{array}$ & $11 \%$ & $39 \%$ & $33 \%$ & $15 \%$ & $2 \%$ \\
\hline $\begin{array}{l}\text { Prohibición de la esclavitud, servidumbre y trata de esclavos; } \\
\text { prohibición de torturas, tratos crueles, inhumanos y degradantes }\end{array}$ & $19 \%$ & $39 \%$ & $27 \%$ & $14 \%$ & $2 \%$ \\
\hline $\begin{array}{l}\text { Igualdad ante la ley, protección de la ley y prohibición de la } \\
\text { discriminación }\end{array}$ & $14 \%$ & $37 \%$ & $35 \%$ & $12 \%$ & $2 \%$ \\
\hline Prohibición de detención, apresamiento y destierro arbitrario & $6 \%$ & $23 \%$ & $36 \%$ & $25 \%$ & $9 \%$ \\
\hline Derecho de propiedad & $10 \%$ & $23 \%$ & $30 \%$ & $28 \%$ & $10 \%$ \\
\hline $\begin{array}{l}\text { Ser oído públicamente con justicia por tribunales indepen- } \\
\text { dientes e imparciales }\end{array}$ & $8 \%$ & $24 \%$ & $31 \%$ & $26 \%$ & $11 \%$ \\
\hline $\begin{array}{l}\text { Presunción de inocencia y recurso efectivo ante los tribunales } \\
\text { nacionales }\end{array}$ & $6 \%$ & $20 \%$ & $30 \%$ & $29 \%$ & $15 \%$ \\
\hline $\begin{array}{l}\text { Protección de la ley ante injerencias o ataques arbitrarios a la } \\
\text { vida privada, honra y reputación }\end{array}$ & $4 \%$ & $19 \%$ & $38 \%$ & $26 \%$ & $13 \%$ \\
\hline $\begin{array}{l}\text { Derecho a circular libremente y a elegir el país de su } \\
\text { residencia }\end{array}$ & $11 \%$ & $36 \%$ & $35 \%$ & $14 \%$ & $4 \%$ \\
\hline Derecho a la nacionalidad & $23 \%$ & $35 \%$ & $28 \%$ & $12 \%$ & $2 \%$ \\
\hline Derecho a casarse y formar familia & $22 \%$ & $47 \%$ & $23 \%$ & $7 \%$ & $1 \%$ \\
\hline $\begin{array}{l}\text { Libertad de pensamiento, conciencia y religión; libertad de } \\
\text { opinión y expresión }\end{array}$ & $26 \%$ & $46 \%$ & $19 \%$ & $7 \%$ & $1 \%$ \\
\hline $\begin{array}{l}\text { Libertad de reunión y asociación pacífica; derecho a partici- } \\
\text { par en el gobierno e igualdad de acceso a funciones públicas }\end{array}$ & $13 \%$ & $33 \%$ & $31 \%$ & $18 \%$ & $5 \%$ \\
\hline $\begin{array}{l}\text { Seguridad social y satisfacción de derechos económicos, } \\
\text { sociales y culturales }\end{array}$ & $8 \%$ & $30 \%$ & $33 \%$ & $22 \%$ & $6 \%$ \\
\hline $\begin{array}{l}\text { Derecho al trabajo, libre elección de éste, salario por trabajo } \\
\text { igual, sindicalización }\end{array}$ & $11 \%$ & $33 \%$ & $36 \%$ & $18 \%$ & $2 \%$ \\
\hline
\end{tabular}

Para analizar la percepción del nivel de conocimiento de los derechos, fueron agrupados considerando el «nivel de conocimiento positivo», relacionándolo con el «nivel de desconocimiento» de ellos. Para estos efectos se consideraron los siguientes niveles de conocimiento:

- Nivel de conocimiento positivo: Corresponde al porcentaje superior al $50 \%$ obtenido de la sumatoria de los porcentajes de dos niveles contiguos de conocimiento considerado suficiente: alto («bueno» $\mathrm{y}$ «muy bueno»), medio («regular»y «bueno») y bajo («poco»y «regular»).

- Nivel de desconocimiento: Considera la sumatoria de los porcentajes obtenidos en los niveles "poco» y «muy poco». Estos últimos se considerarán muy alto cuando el porcentaje de desconocimiento obtenido sea igual o superior al $30 \%$; alto, cuando el porcentaje de desconocimiento obtenido sea igual o superior a $20 \%$ e inferior a $30 \%$; medio, cuando el porcentaje de desconocimiento 
Tabla 2. Tabla de análisis del nivel de conocimiento sobre derechos humanos.

\begin{tabular}{|c|c|c|c|c|}
\hline & $\begin{array}{l}\text { Conocimiento } \\
\text { positivo alto }\end{array}$ & $\begin{array}{l}\text { Conocimiento } \\
\text { positivo medio }\end{array}$ & $\begin{array}{l}\text { Conocimiento } \\
\text { positivo bajo }\end{array}$ & Desconocimiento \\
\hline Niveles de conocimiento & Bueno/Muy bueno & Bueno/Regular & Regular/Poco & Poco/Muy poco \\
\hline Muy alto & $50 \%$ o más & & & $X<10 \%$ (Bajo) \\
\hline Alto & $50 \%$ o más & & & $\begin{array}{c}10 \% \leq X<20 \% \\
\text { (Medio) }\end{array}$ \\
\hline Medio alto & & $50 \%$ o más & & $X<10 \%$ (Bajo) \\
\hline Medio & & $50 \%$ o más & & $\begin{array}{c}10 \% \leq X<20 \% \\
\text { (Medio) }\end{array}$ \\
\hline Medio bajo & & $50 \%$ o más & & $20 \% \leq X<30 \%$ (Alto) \\
\hline Bajo & & & $50 \%$ o más & $\begin{array}{c}10 \% \leq X<20 \% \\
\text { (Medio) }\end{array}$ \\
\hline Muy bajo & & & $50 \%$ o más & $20 \% \leq X<30 \%$ (Alto) \\
\hline Insuficiente & & & $50 \%$ o más & $30 \% \leq X$ (Muy alto) \\
\hline
\end{tabular}

obtenido sea igual o superior a $10 \%$ e inferior a 20 ciento; y bajo, cuando el porcentaje de desconocimiento obtenido sea inferior a $10 \%$.

De esta manera, se agruparon los derechos en las siguientes categorías:

- Muy alto: Nivel de conocimiento positivo alto («muy bueno» y «bueno») y nivel de desconocimiento bajo («poco»y «muy poco») inferior al $10 \%$.

- Alto: Nivel de conocimiento positivo alto («muy bueno» y «bueno») y nivel de desconocimiento medio («poco»y «muy poco») igual o superior a $10 \% \mathrm{e}$ inferior a $20 \%$.

- Medio alto: Nivel de conocimiento positivo medio («bueno» y «regular») y nivel de desconocimiento bajo («poco»y «muy poco») inferior al $10 \%$.

- Medio: Nivel de conocimiento positivo medio («bueno»y «regular») y nivel de desconocimiento medio («poco» $\mathrm{y}$ «muy poco») igual o superior al $10 \% \mathrm{e}$ inferior al $20 \%$.

- Medio bajo: Nivel de conocimiento positivo medio («bueno»o «regular») y nivel de desconocimiento alto («poco» $\mathrm{O}$ «muy poco») superior o igual al $20 \%$ e inferior al $30 \%$.

- Bajo: Nivel de conocimiento positivo bajo («regular» o «poco») y nivel de desconocimiento medio («poco»o «muy poco») igual o superior a $10 \%$ e inferior al $20 \%$.

- Muy bajo: Nivel de conocimiento positivo bajo («regular» o «poco») y nivel de 
Tabla 3. Matriz de análisis del nivel de conocimiento sobre derechos humanos

\begin{tabular}{|c|c|c|c|c|c|c|c|c|}
\hline \multirow[b]{2}{*}{ Derecho } & \multicolumn{5}{|c|}{ Nivel de conocimiento positivo } & \multicolumn{3}{|c|}{ Nivel de desconocimiento } \\
\hline & $\begin{array}{l}\text { Muy } \\
\text { bueno }\end{array}$ & Bueno & Regular & Poco & Total & Poco & $\begin{array}{l}\text { Muy } \\
\text { poco }\end{array}$ & Total \\
\hline $\begin{array}{l}\text { Derecho a la vida, libertad, seguridad e igualdad en } \\
\text { dignidad y derechos }\end{array}$ & & $39 \%$ & $33 \%$ & & $72 \%$ & $15 \%$ & $2 \%$ & $17 \%$ \\
\hline $\begin{array}{l}\text { Prohibición de la esclavitud, servidumbre y trata } \\
\text { de esclavos; prohibición de torturas, tratos crueles, } \\
\text { inhumanos y degradantes }\end{array}$ & & $39 \%$ & $27 \%$ & & $66 \%$ & $14 \%$ & $2 \%$ & $16 \%$ \\
\hline $\begin{array}{l}\text { Igualdad ante la ley, protección de la ley y prohibi- } \\
\text { ción de la discriminación }\end{array}$ & & $37 \%$ & $35 \%$ & & $72 \%$ & $12 \%$ & $2 \%$ & $14 \%$ \\
\hline $\begin{array}{l}\text { Prohibición de detención, apresamiento y destierro } \\
\text { arbitrario }\end{array}$ & & & $36 \%$ & $25 \%$ & $61 \%$ & $25 \%$ & $9 \%$ & $34 \%$ \\
\hline Derecho de propiedad & & & $30 \%$ & $28 \%$ & $58 \%$ & $28 \%$ & $10 \%$ & $38 \%$ \\
\hline $\begin{array}{l}\text { Ser oído públicamente con justicia por tribunales } \\
\text { independientes e imparciales }\end{array}$ & & & $31 \%$ & $26 \%$ & $57 \%$ & $26 \%$ & $11 \%$ & $37 \%$ \\
\hline $\begin{array}{l}\text { Presunción de inocencia y recurso efectivo ante los } \\
\text { tribunales nacionales }\end{array}$ & & & $30 \%$ & $29 \%$ & $59 \%$ & $29 \%$ & $15 \%$ & $44 \%$ \\
\hline $\begin{array}{l}\text { Protección de la ley ante injerencias o ataques } \\
\text { arbitrarios a la vida privada, honra y reputación }\end{array}$ & & & $38 \%$ & $26 \%$ & $64 \%$ & $26 \%$ & $13 \%$ & $39 \%$ \\
\hline $\begin{array}{l}\text { Derecho a circular libremente y a elegir el país de su } \\
\text { residencia }\end{array}$ & & $36 \%$ & $35 \%$ & & $71 \%$ & $14 \%$ & $4 \%$ & $18 \%$ \\
\hline Derecho a la nacionalidad & & $35 \%$ & $28 \%$ & & $63 \%$ & $12 \%$ & $2 \%$ & $14 \%$ \\
\hline Derecho a casarse y formar familia & & $47 \%$ & $23 \%$ & & $70 \%$ & $7 \%$ & $1 \%$ & $8 \%$ \\
\hline $\begin{array}{l}\text { Libertad de pensamiento, conciencia y religión; } \\
\text { libertad de opinión y expresión }\end{array}$ & $26 \%$ & $46 \%$ & & & $72 \%$ & $7 \%$ & $1 \%$ & $8 \%$ \\
\hline $\begin{array}{l}\text { Libertad de reunión y asociación pacífica; derecho } \\
\text { a participar en el gobierno e igualdad de acceso a } \\
\text { funciones públicas }\end{array}$ & & $33 \%$ & $31 \%$ & & $64 \%$ & $18 \%$ & $5 \%$ & $23 \%$ \\
\hline $\begin{array}{l}\text { Seguridad social y satisfacción de derechos econó- } \\
\text { micos, sociales y culturales }\end{array}$ & & $30 \%$ & $33 \%$ & & $63 \%$ & $22 \%$ & $6 \%$ & $28 \%$ \\
\hline $\begin{array}{l}\text { Derecho al trabajo, libre elección de éste, salario por } \\
\text { trabajo igual, sindicalización }\end{array}$ & & $33 \%$ & $36 \%$ & & $69 \%$ & $18 \%$ & $2 \%$ & $20 \%$ \\
\hline
\end{tabular}

desconocimiento alto («poco»o «muy poco») igual o superior a $20 \%$ e inferior al $30 \%$.

- Insuficiente: Nivel de conocimiento positivo bajo («regular» $\mathrm{o}$ «poco») y nivel de desconocimiento muy alto («poco»o «muy poco») igual o superior al $30 \%$.

Posteriormente, se elaboró una tabla para analizar los derechos, como se aprecia en la tabla 2. Luego, se elaboró una matriz en la que se vaciaron los datos, en orden a facilitar su análisis, como se puede apreciar en la tabla 3. Tanto la elaboración de la tabla como de la matriz de análisis permitieron categorizar los derechos de acuerdo a 
Tabla 4. Proceso de categorización de los derechos humanos.

\begin{tabular}{|ll|}
\hline Nivel de conocimiento & Derechos \\
\hline Muy alto & Libertad de pensamiento, conciencia y religión; libertad de opinión y expresión \\
\hline Alto & No hay derechos que calcen en esta categoría \\
\hline Medio alto & Derecho a casarse y formar familia \\
\hline Medio & $\begin{array}{l}\text { Derecho a la vida, libertad, seguridad e igualdad en dignidad y derechos / Prohibición de la esclavitud, ser- } \\
\text { vidumbre y trata de esclavos; prohibición de torturas, tratos crueles, inhumanos y degradantes / Igualdad } \\
\text { ante la ley, protección de la ley y prohibición de la discriminación }\end{array}$ \\
\hline Medio bajo & $\begin{array}{l}\text { Libertad de reunión y asociación pacífica; derecho a participar en el gobierno e igualdad de acceso a fun- } \\
\text { ciones públicas / Seguridad social y satisfacción de derechos económicos, sociales y culturales / Derecho al } \\
\text { trabajo, libre elección de éste, salario por trabajo igual, sindicalización }\end{array}$ \\
\hline Bajo & $\begin{array}{l}\text { Derecho a circular libremente y a elegir el país de su residencia / Derecho a la nacionalidad } \\
\text { No hay derechos que calcen en esta categoría }\end{array}$ \\
\hline Muy bajo & $\begin{array}{l}\text { Prohibición de detención, apresamiento y destierro arbitrario / Derecho de propiedad / Ser oído públi- } \\
\text { camente con justicia por tribunales independientes e imparciales / Presunción de inocencia y recurso } \\
\text { efectivo ante los tribunales nacionales / Protección de la ley ante injerencias o ataques arbitrarios a la vida } \\
\text { privada, honra y reputación }\end{array}$ \\
\hline Insuficiente & \\
\hline
\end{tabular}

su nivel de conocimiento declarado por los estudiantes encuestados, como se aprecia en la tabla 4 .

Realizando un análisis de estos resultados, de acuerdo a la categorización realizada, es posible concluir que los esfuerzos deben focalizarse en la enseñanza de los derechos ubicados en las categorías «insuficiente», «bajo» y «medio bajo». De esta manera, el derecho que tendría el nivel de conocimiento más alto de acuerdo con la apreciación de la mayoría de los estudiantes «bueno» y «muy bueno» - el $72 \%$ - es la «libertad de pensamiento, conciencia y religión y libertad de opinión y expresión». El nivel de desconocimiento es también bajo, pues entre quienes declaran conocer el derecho «poco» (7\%) o «muy poco» (1\%) alcanzan sólo el $8 \%$.

Respecto del «derecho a casarse y formar familia», la mayoría - el $70 \%$ - considera que su nivel de conocimiento es «bueno» (47\%) o «regular» (23\%). La diferencia entre quienes consideran su nivel de conocimiento como «muy bueno» es casi la misma que quienes lo consideran «regular», tal como se señalara anteriormente, correspondiendo al $22 \%$. En términos negativos, quienes conocen el derecho «poco» ( $7 \%)$ o «muy poco» ( $1 \%$ ) suman sólo el $8 \%$.

Los derechos respecto de los cuales la mayoría de los estudiantes considera que su nivel de conocimiento es «bueno» o «regular» son: «derecho a la vida libertad, seguridad e igualdad en dignidad y derechos», "prohibición de la esclavitud, servidumbre y trata de esclavos y prohibición de torturas, tratos crueles, inhumanos y degradantes», "derecho a circular libremente y a elegir el país de su residencia», "derecho a una nacionalidad», «igualdad ante la ley, protección de la ley y prohibición de la discrimina- 
ción», «libertad de reunión y asociación pacífica y derecho a participar en el gobierno e igualdad de acceso a funciones públicas», «derecho al trabajo, libre elección de éste, salario por trabajo igual, sindicalización» y «seguridad social y satisfacción de derechos económicos, sociales y culturales».

Estos derechos también presentan un nivel de desconocimiento menor al $20 \%$; en tanto, un total de $17 \%$ considera que su nivel de conocimiento es «poco» $(15 \%)$ o «muy poco» $(2 \%)$ sobre el «derecho a la vida libertad, seguridad e igualdad en dignidad y derechos». Por su parte, el $16 \%$ declara conocer «poco» (14\%) o «muy poco» (2\%) respecto a la "prohibición de la esclavitud, servidumbre y trata de esclavos y prohibición de torturas, tratos crueles, inhumanos y degradantes». En cuanto a la «igualdad ante la ley, protección de la ley y prohibición de la discriminación», un total de $14 \%$ de los estudiantes encuestados señala conocer "poco» (12\%) o «muy poco» $(2 \%)$. Respecto del «derecho a circular libremente y a elegir el país de su residencia», el $18 \%$ considera que conoce "poco» (14\%) o «muy poco» (4\%) sobre este derecho. Sobre el «derecho a la nacionalidad», un total de $14 \%$ considera conocer «poco» (12\%) o «muy poco» $(2 \%)$.

Una categoría intermedia son los siguientes derechos que, si bien tienen un nivel de conocimiento «bueno» o "regular», tienen un nivel de desconocimiento "poco» o «muy poco» superior o igual al $20 \%$. En esta categoría se encuentran la «libertad de reunión y asociación pacífica y derecho a participar en el gobierno e igualdad de acceso a funciones públicas», respecto del cual un total de $23 \%$ de los estudiantes encuestados tienen un conocimiento que califican como "poco» (18\%) o «muy poco» (5\%). También el «derecho al trabajo, libre elección de éste, salario por trabajo igual y sindicalización», donde el $20 \%$ de los encuestados señala conocer "poco» $(18 \%)$ o «muy poco» (2\%), lo que se condice con el conocimiento de los derechos de «seguridad social y satisfacción de derechos económicos, sociales y culturales», en que el $28 \%$ señala conocer «poco» $(22 \%)$ o «muy poco» (6\%) acerca de este derecho.

Por su parte, los derechos respecto de los cuales los estudiantes señalan poseer un nivel de conocimiento que califican como «regular»o «poco» son la «prohibición de detención, apresamiento y destierro arbitrario», el «derecho de propiedad», el de «ser oído públicamente con justicia por tribunales independientes e imparciales», la «presunción de inocencia y recurso efectivo ante los tribunales nacionales» y la «protección de la ley ante injerencias o ataques arbitrarios a la vida privada, honra y reputación».

Coincidentemente, estos derechos son aquéllos que también presentan un porcentaje de desconocimiento superior al $30 \%$, considerando las categorías «poco»o «muy poco». Así, respecto a la "prohibición de detención, apresamiento y destierro arbitrario», el $34 \%$ declara que su nivel de conocimiento respecto a este derecho es «poco» $(25 \%)$ o «muy poco» ( $9 \%)$; en cuanto al «derecho de propiedad», el $38 \%$ señala conocer «poco» $(28 \%)$ o «muy poco» $(10 \%)$ este derecho; sobre el derecho a «ser 


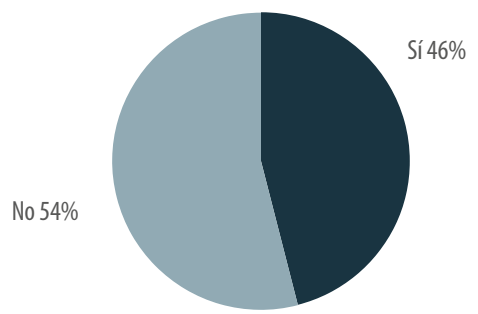

Figura 5. En su opinión, ¿en la UFRO se enseña sobre el respeto a los derechos humanos?

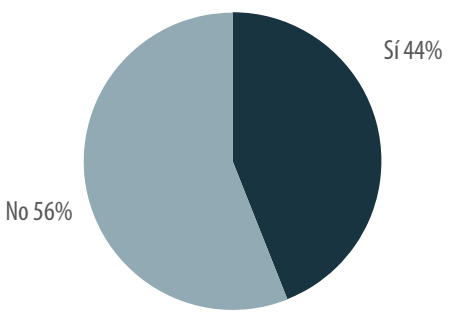

Figura 6. Si se ofertara un curso de derechos humanos optativo, ¿usted lo tomría?

oído públicamente con justicia por tribunales independientes e imparciales», el $37 \%$ aprecia su conocimiento en las categorías «poco» $(26 \%)$ o «muy poco» $(11 \%)$; respecto a la "presunción de inocencia y recurso efectivo ante los tribunales nacionales», el $44 \%$ aprecia su conocimiento en las categorías «poco» (29\%) o «muy poco» (15\%); para la «protección de la ley ante injerencias o ataques arbitrarios a la vida privada, honra y reputación», el $39 \%$ aprecia su conocimiento en las categorías "poco» $(26 \%)$ o «muy poco» $(13 \%)$.

Respecto a si, en opinión de los encuestados, en la Universidad de La Frontera se enseña sobre el respeto de los derechos humanos, el 54,3\% señala que no, frente al $45,7 \%$ que afirma lo contrario (figura 5). La pregunta inmediatamente siguiente formulada consistente en «isi se ofertara un curso electivo de derechos humanos usted lo tomaría?». Una cifra casi similar $(55,7 \%)$ se manifiesta negativamente, tal como muestra la figura 6.

Esto no necesariamente constituye una contradicción, pues el abordaje en la formación estudiantil en derechos humanos no ha de ser forzosamente a través de asignaturas electivas.

Frente a la pregunta 11, en que se les consulta a los estudiantes si consideran que las asignaturas de su carrera incorporan elementos de derechos humanos, el 62,4\% responde afirmativamente (figura 7). Le sigue la pregunta 12, en que se les pregunta si consideran que las siguientes unidades de la universidad le han entregado herramientas respecto a los derechos humanos. Los estudiantes responden señalando que en mayor medida son las carreras, luego las facultades y finalmente la universidad, en ese orden de importancia decreciente, quienes entregan herramientas respecto a los derechos humanos. De todas maneras, la apreciación negativa es alta respecto a la universidad y a nivel de facultad ( «nada o casi nada»). Respecto de las carreras, las dimensiones «bastante o mucho» (34\%) y «algo» (32\%) suman $66 \%$, cifra cercana al $62,4 \%$ que respondió afirmativamente la pregunta anterior, tal como puede evidenciarse en figura 8. 


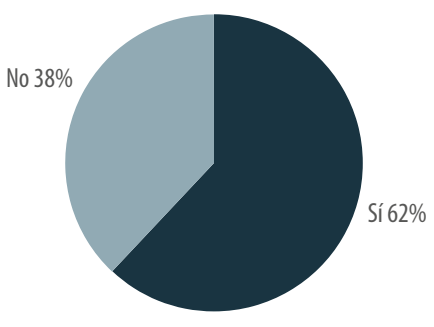

Figura 7. ¿Consideras que las asignaturas de tu carrera incorporan elementos de derechos humanos?

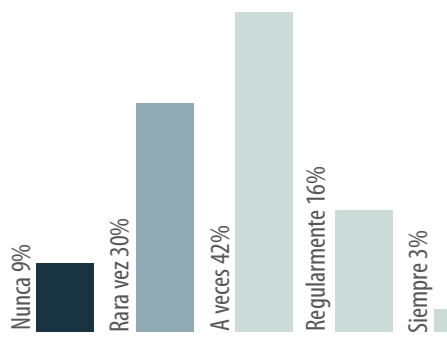

Figura 9. ¿Se informa usted sobtre la situación de los derechos humanos en el mundo?

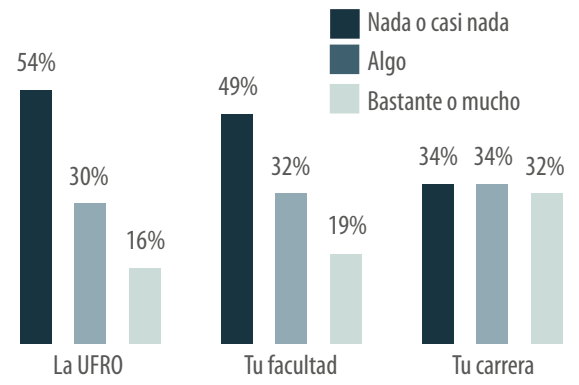

Figura 8. ¿Consideras que las siguientes unidades te han entregado herramientas respecto a los derechos humanos?
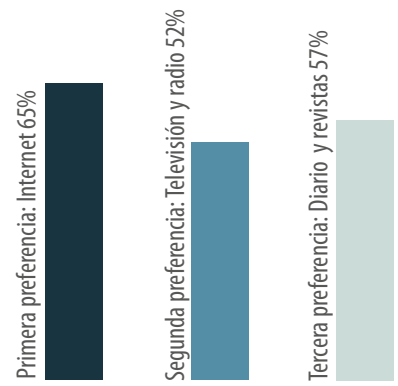

Figura 10. ¿A través de qué medio se informa usted de los derechos humanos?

En otra categoría de preguntas, se consulta a los estudiantes sobre si se informan de la situación de los derechos humanos en el mundo (pregunta 13), contestando la mayoría, el $42 \%$, que «a veces» y el $30 \%$ que «rara vez» (figura 9). En cuanto a los medios a través de los cuales se informan los estudiantes acerca de los derechos humanos, se les pidió indicar los tres medios que utilizan de manera preferente entre las siguientes alternativas: revistas y libros especializados, diarios y revistas de carácter general, televisión y radio, internet, y ningún medio en particular. La primera preferencia es «internet», con el $65 \%$; la segunda es «televisión y radio», con el $52 \%$, y la tercera «diarios y revistas de carácter general» con el $57 \%$, tal como se puede apreciar en la figura 10.

Esta información es relevante para la toma decisiones en cuanto a las medidas remediales que debieran implementarse para enfrentar estos déficits en educación en derechos humanos. En dicho sentido, es necesario considerar que los estudiantes, por una parte, no se encontrarían dispuestos a tomar un electivo sobre derechos humanos, y por otra, que se informan principalmente a través de internet, de modo que sería eficiente utilizar dicho canal para impartir, por ejemplo, un curso en modalidad e-learning, motivado por incentivos diversos a los créditos, como que sea 


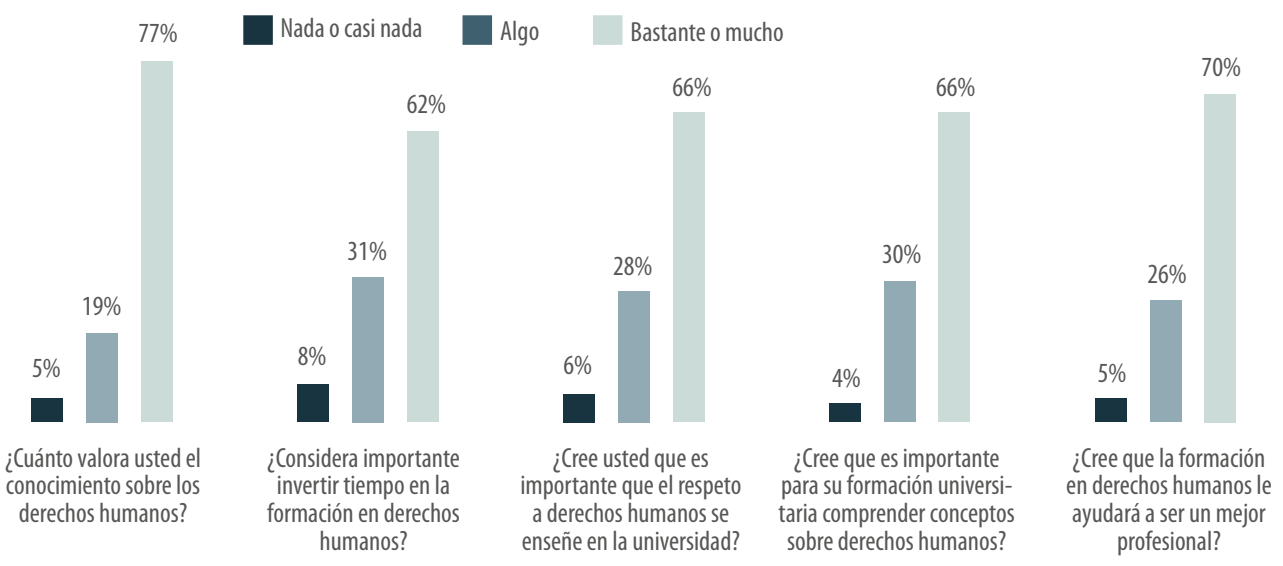

Figura 11. Valoración del conocimiento sobre derechos humanos.

imputado a horas extracurriculares o que traiga aparejada alguna certificación para los estudiantes.

Por otro lado, en la pregunta 15 se contienen cinco preguntas destinadas a conocer la valoración del conocimiento en derechos humanos que poseen los estudiantes encuestados, correspondiendo a las siguientes preguntas: ¿cuánto valora usted el conocimiento sobre los derechos humanos? ¿Considera importante invertir tiempo en la formación en derechos humanos? ¿Cree usted que es importante que el respeto a los derechos humanos se enseñe en la universidad? ¿Cree que es importante para su formación universitaria comprender conceptos sobre derechos humanos? ¿Cree que la formación sobre derechos humanos le ayudará a ser un mejor profesional? De las respuestas de los estudiantes, se percibe una amplia valoración del conocimiento en derechos humanos como elemento importante de su formación universitaria y profesional. El $72 \%$ valora «bastante o mucho» el conocimiento sobre la temática, el $62 \%$ considera «bastante o mucho» importante invertir tiempo en la formación en derechos humanos, el $66 \%$ cree importante para su formación universitaria comprender conceptos sobre derechos humanos y el 70 \% cree que la formación en estas temáticas le ayudará a ser un mejor profesional, tal como se grafica en la figura 11.

Dentro de la batería de preguntas identificadas con el número 16, correspondientes al grado de acuerdo de los estudiantes encuestados respecto de determinadas afirmaciones referentes a temáticas de derechos humanos, se identifican tres grupos de preguntas:

- Aquéllas que dicen relación con afirmaciones provocadoras acerca de preconceptos, prejuicios y caricaturizaciones que se tienen respecto de los derechos humanos: «Los derechos humanos son aquellos que protegen sólo a las minorías sexuales y los pueblos originarios»; «en Chile actualmente no hay problemas de derechos humanos. Eso es cosa del pasado y que lamentablemente 
afecta a otros países»; «en algunas ocasiones es justificable que la policía viole los derechos de una persona si considera que ella tiene información relevante para aclarar un delito»; «los derechos humanos sólo le importan a la izquierda. Es un patrimonio político de ellos»; «los derechos humanos son una pérdida de tiempo».

- Afirmaciones referentes a las violaciones de derechos humanos durante la dictadura cívico-militar: «Es necesario seguir investigando y juzgando a los responsables de las violaciones a los derechos humanos ocurridas en dictadura»; «Chile requiere dar vuelta la página en el tema de los derechos humanos y mirar hacia el futuro».

- Afirmaciones respecto a las medidas de reparación: «Las medidas de reparación sólo constituyen una forma que tienen las personas de aprovecharse del Estado y sacar ventajas»; «es injusto que, si uno es pobre y no mapuche o su familia no sufrió violencia política, no tenga las mismas oportunidades».

El análisis de las respuestas entregadas frente a esta pregunta se realizará siguiendo esta categorización, de manera que, respecto de las afirmaciones contenidas en el primer grupo, la mayoría de los estudiantes no comparten algunos prejuicios y caricaturizaciones que se afirman sobre los derechos humanos, como que sólo protegen a las minorías sexuales y los pueblos originarios ( $83 \%$ ); que en Chile actualmente no hay problemas de derechos humanos, son cosa del pasado y que lamentablemente afecta a otros países ( $85 \%$ ); que los derechos humanos sólo le importan a la izquierda y son patrimonio político de ellos ( $75 \%)$, o que son una pérdida de tiempo (90\%). Llama la atención que sólo el $60 \%$ señala estar «muy en desacuerdo o en desacuerdo» con la afirmación de que «en algunas ocasiones es justificable que la policía viole los derechos de una persona si considera que ella tiene información relevante para aclarar un delito». Esto contrasta con el conocimiento declarado respecto a la "prohibición de la esclavitud, servidumbre y trata de esclavos y prohibición de torturas, tratos crueles, inhumanos y degradantes», donde la mayoría (66\%) de los estudiantes considera que su nivel de conocimientos es «bueno» $(39 \%)$ o «regular» $(27 \%)$, y sólo el $16 \%$ declara conocer «poco» (14\%), o «muy poco» $(2 \%)$.

Respecto a las afirmaciones referentes a las violaciones de derechos humanos durante la dictadura cívico-militar, la mayoría (61\%) de los estudiantes también señalan estar de acuerdo o muy de acuerdo con la afirmación de que «es necesario seguir investigando y juzgando a los responsables de las violaciones a los derechos humanos ocurridas en dictadura». El porcentaje de mayoría (59\%) es coherente con el desacuerdo respecto a la afirmación de que «Chile requiere dar vuelta la página en el tema de los derechos humanos y mirar hacia el futuro». Estas respuestas se deben analizar junto con las dadas respecto de las afirmaciones, consideradas al final de la 


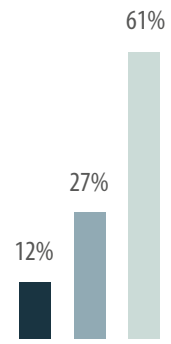

Es necesario seguir investigando y juzgando a los responsables de las violaciones a los derechos humanos ocurridas en dictadura.

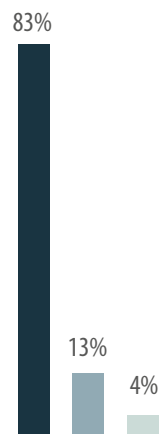

Los derechos humanos son solo aquellos que protegen a las minorías sexuales y los pueblos originarios.

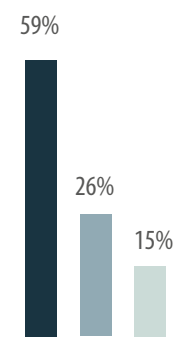

Chile requiere dar vuelta la página en el tema de los derechos humanos y mirar hacia el futuro.

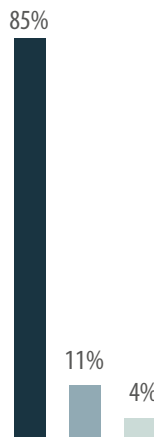

En Chile actualmente no hay problermas de derechos humanos. Eso es cosa del pasado y que lamentablemente afecta a otros países.

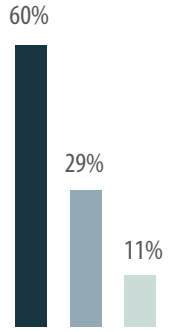

En algunas ocasiones es justificable que la policía viole los derechos de una persona si considera que ella tiene información relevante para aclarar un delito

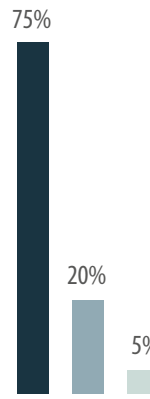

Los derechos humanos solo le importan a la izquierda. Es un patrimonio político de ellos.

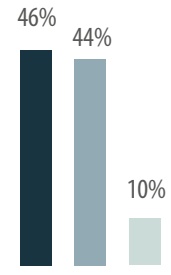

Las medidas de reparación solo constituyen una forma que tienen las personas de aprovecharse del Estado y sacar ventajas.

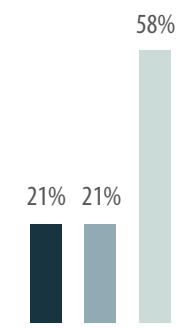

Es injusto que si uno es pobre y no mapuche o su familia no sufrió violencia política no tenga las mismas oportunidades.

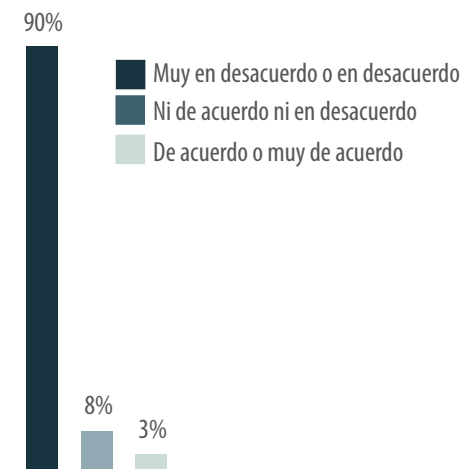

Los derechos humanos son una pérdida de tiempo.

Figura 12. Grado de acuerdo respecto de afirmaciones sobre derechos humanos.

encuesta, sobre la justificación de la comisión de violaciones a los derechos humanos en el contexto sociopolítico del año 1973: «En el contexto sociopolítico del año 1973 no se justificaba violar los derechos humanos bajo ninguna circunstancia», la mayoría ( $72 \%)$ señala su acuerdo con la afirmación. Destaca eso sí que una cifra no despreciable ( $28 \%)$ manifiesta su desacuerdo. En cuanto a la afirmación: «Dado el contexto sociopolítico del año 1973, resultó necesario violar los derechos humanos de algunas personas para alcanzar un bien mayor», una amplia mayoría (91\%) se manifiesta en desacuerdo.

En el tercer grupo de afirmaciones, las cuales se refieren a las medidas de reparación, hay varias cosas interesantes. Si bien la mayoría ( $46 \%)$ se manifiesta «en desacuerdo o muy en desacuerdo» respecto a la afirmación de que éstas «sólo constituyen una forma que tienen las personas de aprovecharse del Estado y sacar ventajas», 


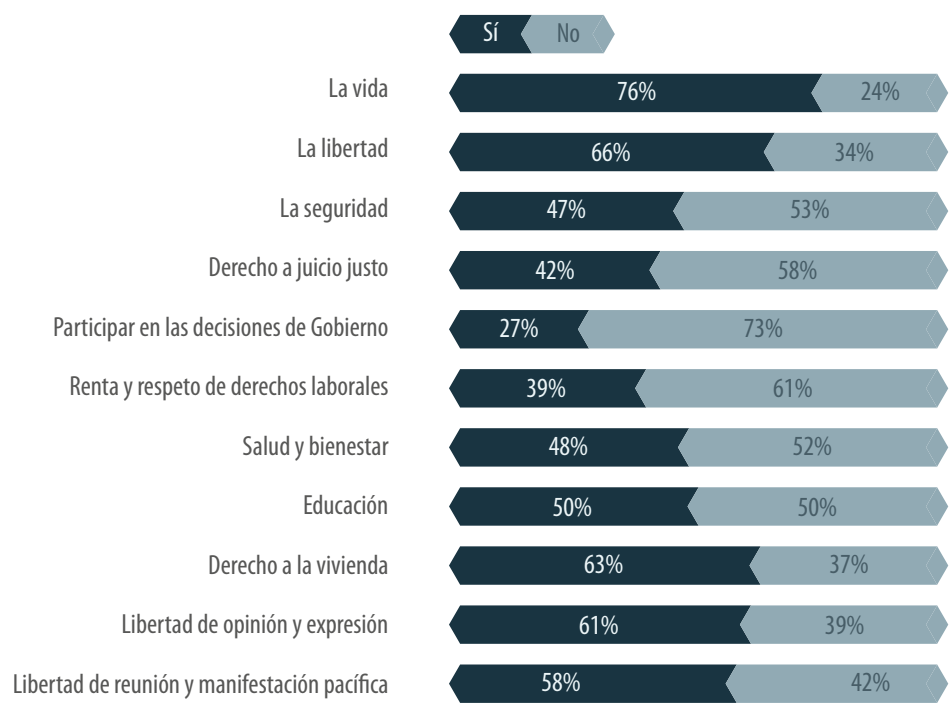

Figura 13. ¿Se protegen los siguientes derechos en Chile?

es interesante el hecho de que un porcentaje de similar relevancia (44\%) no se manifiesta «ni de acuerdo, ni en desacuerdo». Del mismo modo, la frase provocativa «es injusto que si uno es pobre y no mapuche o su familia no sufrió violencia política no tenga las mismas oportunidades», generó como reacción que la mayoría ( $58 \%$ ) de los encuestados se manifiesta «de acuerdo o muy de acuerdo», haciendo referencia a lo que se manifestaba sobre ciertas becas, como la beca Valech o Indígena, respecto de la cual resulta interesante que, al tratarse de tópicos que «afectan» de manera directa a los estudiantes, la reacción puede llegar a ser opuesta a lo declarado. Los porcentajes se pueden apreciar en el figura 12.

Por su parte, la pregunta 17 hace referencia a si los estudiantes encuestados creen que en Chile se protege determinados derechos, con la intención de conocer su apreciación respecto de la protección de once derechos, a saber: la vida, la libertad, la seguridad, el derecho a un juicio justo, el derecho a participar en las decisiones de gobierno, el derecho a la renta y el respeto de derechos laborales, el derecho a la salud y al bienestar, el derecho a la educación, el derecho a la vivienda, la libertad de opinión y expresión, y la libertad de reunión y manifestación pacífica. Entre los resultados obtenidos para esta pregunta, sorprende verificar que los derechos a la seguridad, a un juicio justo, a participar en las decisiones de Gobierno, a la renta y el respeto de los derechos laborales, a la salud y el bienestar, y el derecho a la educación, se entienden por el $50 \%$ o más de los encuestados como no protegidos, según se aprecia en la figura 13.

En otra categoría, la pregunta 18 contiene tres afirmaciones respecto de las cuales los estudiantes encuestados deben indicar su grado de acuerdo, consultándoles sobre el respeto de los derechos de los pueblos originarios, a través de la afirmación «en la 


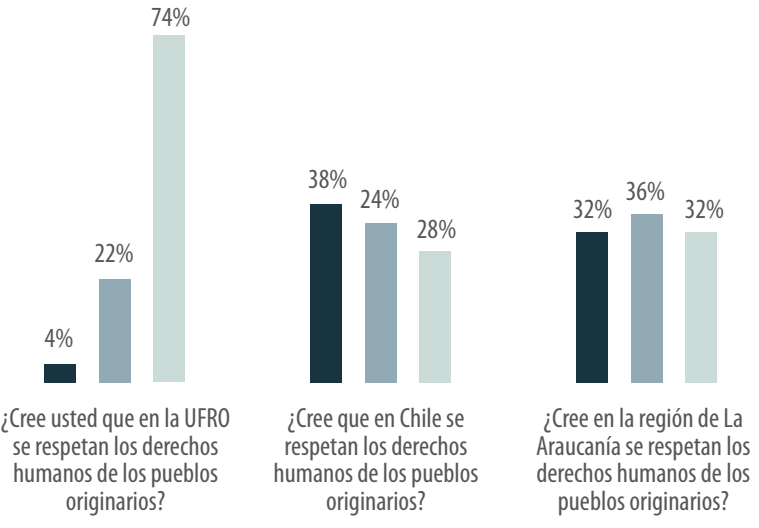

Figura 14. Derechos humanos de los pueblos originarios.
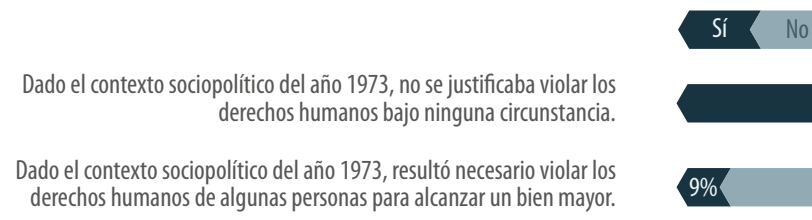

Dado el contexto sociopolítico del año 1973, no se justificaba violar los derechos humanos bajo ninguna circunstancia.

Figura 15. ¿Está de acuerdo con las siguientes afirmaciones?

UFRO se respetan los derechos de los pueblos originarios», respecto de la cual el $74 \%$ se manifiesta «de acuerdo o muy de acuerdo», seguida del $22 \%$ que señala no estar «ni de acuerdo ni en desacuerdo» y una postura minoritaria del $4 \%$ que señala estar «muy en desacuerdo o en desacuerdo». Por su parte, sobre la afirmación «en Chile se respetan los derechos de los pueblos originarios», las opiniones de los estudiantes se encuentran muy divididas, ya que la opinión mayoritaria (38\%) se manifiesta «muy en desacuerdo o en desacuerdo», seguido del $34 \%$ que señala no estar «ni de acuerdo ni en desacuerdo», y finalmente una postura minoritaria ( $28 \%)$ que señala estar «de acuerdo o muy de acuerdo». Por último, respecto de la afirmación «en la región de La Araucanía se respetan los derechos de los pueblos originarios», la mayoría, que corresponde al $36 \%$, señala no estar «ni de acuerdo ni en desacuerdo», y las posturas extremas «de acuerdo o muy de acuerdo» $\mathrm{y}$ «muy en desacuerdo o en desacuerdo» se encuentran empatadas en $32 \%$, tal como se evidencia en el figura 14.

Por último, en la pregunta 19 se consulta sobre la apreciación de los estudiantes respecto de la justificación en la comisión de violaciones a los derechos humanos en el contexto sociopolítico del año 1973, a través de dos afirmaciones respecto de las cuales debían indicar si estaban de acuerdo o en desacuerdo. Así, respecto de la afirmación «en el contexto sociopolítico del año 1973 NO se justificaba violar los derechos humanos bajo ninguna circunstancia», el $72 \%$ de los estudiantes encuestados 
señala estar de acuerdo, mientras que el $28 \%$-cifra no despreciable- se manifiesta en desacuerdo. En cuanto a la afirmación «dado el contexto sociopolítico del año 1973, resultó NECESARIO violar los derechos humanos de algunas personas para alcanzar un bien mayor», un amplio $91 \%$ se manifiesta en desacuerdo, como se muestra en el figura 15.

\section{Reflexiones finales}

Desde el retorno a la democracia, Chile sostenidamente ha avanzado en el reconocimiento de los derechos humanos, de modo que, desde el año 1990, nuestro país ha sido bastante proactivo en la suscripción de tratados internacionales y ha avanzado en forma sostenida y significativa en el aseguramiento y vigencia de los derechos para todos sus ciudadanos, lo que significa un gran esfuerzo para el Estado, en tanto el desarrollo de valores democráticos se encuentra directamente vinculado con la implementación de políticas públicas que buscan garantizar estos derechos, ya que «reconocimiento y respeto supone empoderar a la ciudadanía, partiendo con una definición clara de sus derechos y la forma como hacerlos efectivos» (PNUD, 2014: 181).

Así, «en términos comparados y de acuerdo con indicadores internacionales, se ha avanzado fuertemente en garantizar el derecho al trabajo, la educación, la salud y el acceso a condiciones básicas de vida» (PNUD, 2014: 181). La garantía de estos derechos necesariamente incluye preparar a los ciudadanos para que enfrenten de manera exitosa los desafíos democráticos y la vida cívica, labor que comprende fundamentalmente a las instituciones de enseñanza, respecto de las cuales la universidad tiene un papel preponderante, sobre todo si se considera que a partir del año 2016 comenzó a regir la gratuidad universitaria respecto de ciertas instituciones de educación superior, quienes tienen un rol social que cumplir al recibir estudiantes de diversos sectores económicos, en su mayoría la primera generación de sus respectivas familias en tener acceso a la educación superior.

De este modo, la responsabilidad del Estado no se agota con la suscripción de tratados y otros instrumentos, pues quedan bastantes temas por abordar (véase INDH, 2015), entre ellos, la implementación de la educación en derechos humanos, necesaria para formar ciudadanos comprometidos con el respeto, promoción y protección de los mismos, y como se puede apreciar de lo descrito en este trabajo, para formar ciudadanos comprometidos con el sistema democrático, en tanto el fenómeno de la alta abstención electoral también forma parte del déficit causado por la falta de educación en derechos humanos. Dentro de los resultados obtenidos, uno de los más interesantes dice relación con que el $73 \%$ de los estudiantes encuestados considera que en Chile no se protege el derecho a participar en las decisiones de gobierno, de modo que al no conocer los derechos, se tiende a pensar que ellos no están siendo protegidos. 
De esta manera, se hace necesario que la educación secundaria entregue herramientas básicas mínimas en materia de respeto a los derechos humanos y los valores democráticos, para que posteriormente sea la educación universitaria la que profundice los conocimientos y valores ya adquiridos, a través de la correlación con las carreras de pregrado que escojan los estudiantes, ya que es innegable frente a los resultados del presente estudio que los estudiantes ingresan a la universidad no poseen estos conocimientos mínimos.

El estudio arroja luces sobre cómo los estudiantes que ingresan a primer año en la Universidad de La Frontera califican su nivel de conocimiento en derechos humanos y reaccionan frente a afirmaciones que relacionan tópicos de derechos humanos con el ejercicio de ciertos derechos políticos. Para ello, se analizaron los cambios en el currículum de formación ciudadana, la importancia de la formación ciudadana, específicamente en derechos humanos y la alta abstención electoral como consecuencia - al menos remota - a la que contribuye, en parte, la formación cívica insuficiente.

Los resultados nos permiten concluir que a pesar de que los estudiantes al terminar la educación media debiesen ser capaces de conocer los principales fundamentos e instituciones de la democracia, comprender qué son los derechos Humanos y qué rol desempeñan en un Estado democrático, relacionándolo con la participación ciudadana y sus elementos, los cambios en el currículum de formación ciudadana no han permitido que los estudiantes - al menos aquéllos que ingresan a primer año a la Universidad de La Frontera- logren eficientemente los objetivos formativos mínimos en el área de educación en derechos humanos, entendiendo esto como el conocimiento de aquéllos reconocidos en la Declaración Universal de Derechos Humanos de 1948. Esta situación es preocupante, toda vez que si bien las causas del abstencionismo electoral son múltiples y afectan a todos - aunque en mayor medida a los jóvenes-, la literatura citada demuestra una relación directa entre la formación cívica y la participación ciudadana en su componente más importante, como es la participación electoral, de modo que implementándose una real educación en derechos humanos ésta tendrá, sin lugar a dudas, una incidencia positiva en este indicador.

Finalmente, insistimos en que resulta en extremo preocupante la opinión que tienen los estudiantes respecto a la pregunta de si creen que en Chile se protege el derecho a "participar en las decisiones de gobierno», en el cual, como hemos reiterado, el $73 \%$ de los encuestados manifestó en forma negativa, la cual es lejos la más alta de todas, seguida por el derecho a la renta y el respeto de los derechos laborales con el $61 \%$, lo que relacionado con la categorización «libertad de reunión y asociación pacífica y derecho a participar en el gobierno e igualdad de acceso a funciones públicas», que aparece calificado con un nivel de conocimiento «medio bajo», lleva a deducir que los estudiantes, al desconocer el contenido de este derecho, desconocen también la existencia de protección y promoción del mismo, lo que puede ser una causa para no ejercerlo (abstención electoral), lo cual patente la necesidad de establecer a 
la participación ciudadana como derecho fundamental, principio constitucional y fin del Estado, constituyendo un respaldo a la legitimidad de los gobernantes y una forma de hacer frente a los procesos de movilización ciudadana que exigen una mayor participación en las decisiones (Morales, 2016b), de modo que con mayor y mejor formación ciudadana, se logrará mayor participación y que aquellos derechos por los que tantos luchan y han luchado logren ser «una verdad evidente» para todas y todos.

\section{Referencias}

Agencia de Calidad de la Educación (2016). Formación ciudadana en el sistema escolar chileno: Una mirada a las prácticas actuales y recomendaciones de mejora. Santiago.

Alexy, Robert (2003). «Los derechos fundamentales en el Estado constitucional democrático». En Miguel Carbonell (editor), Neoconstitucionalismo. Madrid: Trotta.

Blanco, Rosa (2008). «Construyendo las bases de la inclusión y la calidad de la educación en la primera infancia». Revista de Educación, 347: 33-54. Disponible en http://bit.ly/2yhmMZz.

BLENGIO, Mariana (2013). «La protección jurídica del derecho humano a la educación y su proyección en el ámbito internacional». Sociedade e Cultura, 16 (2): 289-298. Disponible en http://bit.ly/2ygCnbA.

Boni, Alejandra, Jadicha Sow y Amparo Hofmann-PInilla (2012). «Educando para la ciudadanía global: Una experiencia de investigación cooperativa entre docentes y profesionales de las ONGD». Estudios sobre Educación, 23: 63-81. Disponible en http://bit.ly/2ygIpcq.

Chuaqui, Tomás (2007). «Participación electoral obligatoria: Una defensa». En Arturo Fontaine y otros (editores), Modernización del régimen electoral chileno. Santiago: PNUD.

Contreras, Gonzalo y Patricio Navia (2913). «Diferencias generacionales en la participación electoral en Chile, 1988-2010». Revista de Ciencia Política, 33 (2): 419441. DOI: 10.4067/So718-090X2013000200001.

Cox, Cristian (2011). «Construcción política de reformas curriculares: El caso de Chile en los noventa». Profesorado, 10 (1): 1-24. Disponible en http://bit.ly/2ygDoQW.

Emmert, Simone (2011). «Education in terms of human rights». Procedia, 12: 346-361. DOI: 10.1016/j.sbspro.2011.02.044.

EsPejo, Nicolás (2014). «El derecho a la educación en el derecho internacional de los derechos humanos». Revista Pedagogía Universitaria y Didáctica del Derecho, 1 (1): 20-35. DOI: 10.5354/0719-5885.2014.35961.

FonseCA, Gonzalo (2015). «Distancia entre el currículo de educación secundaria y terciaria: Desafío para la política pública e instituciones». Revista Pedagogía Universitaria y Didáctica del Derecho, 1 (2): 57-68. DOI: 10.5354/0719-5885.2014.35981. 
GonZÁLEZ, Erika (2012). «Educación de la cultura política en los manuales escolares de educación para la ciudadanía y los derechos humanos». Profesorado, 16 (2): 501516. Disponible en http://bit.ly/2yhkglU.

Haime, Agustina (2017). «¿Qué explica la participación electoral en América Latina? Un estudio sobre el efecto de la actitud de los ciudadanos hacia el proceso electoral». Revista de Ciencia Política, 37 (1): 69-93.DOI: 10.4067/So718-090X2017000100004. Instituto Nacional de Derechos Humanos (2015). Informe anual 2015: Situación de los derechos humanos en Chile. Santiago. Disponible en http://bit.ly/2ygJtwT.

International Association for the Evaluation of Educational AchieveMENT, IEA (2009). Estudio internacional de educación cívica y formación ciudadana (ICCS): Primer informe nacional de resultados. Santiago: Unidad de Currículum y Evaluación, Ministerio de Educación.

LATAPí, Pablo (2009). «El derecho a la educación: Su alcance, exigibilidad y relevancia para la política educativa». Revista Mexicana de Investigación Educativa, 14 (40): 255-287. Disponible en http://bit.ly/2yhkIR8.

Leihy, Peodair y José Miguel Salazar (2017). «The moral dimension in Chilean higher education's expansion». Higher Education, 74 (1): 147-161. DOI: 10.1007/ s10734-016-0034-8.

Leiva, Pedro (1999). «Educación para la democracia: Recuento de experiencias internacionales». Estudios Pedagógicos, 25: 91-112. DOI: 10.4067/ So718-07051999000100006.

MCCowan, Tristan (2012). «Is there a universal right to higher education?». British Journal of Educational Studies, 6o (2):111-128. DOI: 10.1080/00071005.2011.648605.

Miтомa, Glenn (2014). "The character of contemporary history: Human rights history and early modern violence». History, 99 (336): 549-565. DOI: 10.1111/1468-229X.12059.

Morales, Salomé (2015). «Abstención electoral y nuevas formas de participación política de los jóvenes chilenos». Perspectivas de la Comunicación, 8 (2): 143-170. Disponible en http://bit.ly/2ygYaQD.

Morales, Soledad (2016a). «Instrumentos de participación ciudadana en Chile (Ley 20.500): Un análisis crítico en torno al accountability social». Tesis para optar al grado de Magíster en Ciencias Sociales Aplicadas, Universidad de La Frontera, Temuco.

-. (2016b). «Participación ciudadana y accountability: Reflexiones sobre la experiencia comparada en Chile y Colombia». Revista Jurídicas, 13 (2): 100-113. DOI: 10.17151/jurid.2016.13.2.8.

MuÑoz, Carlos, María SÁNCHez y Nelson VÁsquez (2013). «Percepciones del estudiantado sobre la democracia y los derechos humanos al finalizar la educación general básica: Un estudio desde las aulas de historia». Psicoperspectivas, 12 (1): 97-117. Disponible en http://bit.ly/2yhdg8s. 
Navia, Patricio y Camilla UlRiksen (2017). «Tuiteo, luego voto: El efecto del consumo de medios de comunicación y uso de redes sociales en la participación electoral en Chile en 2009 y 2013». Cuadernos.info, 40: 71-88. DOI: 10.7764/cdi.40.1049.

Nogueira, Humberto (2008). «El derecho a la educación y sus regulaciones básicas en el derecho constitucional chileno e internacional de los derechos humanos». Ius et Praxis, 14 (2): 209-269. DOI: 10.4067/So718-00122008000200007.

NoHLEN, Dieter (2004). «La participación electoral como objeto de estudio». Elecciones, 3: 137-157.

Oliva, María Angélica, y Felipe GASCón (2016). «Estandarización y racionalidad política neoliberal: Bases curriculares de Chile». Cadernos CEDES, 36 (100): 301-318. DOI: $10.1590 /$ cco101-32622016171349.

Palma, Eric y Antonia Santos (2015). «Derechos económicos, sociales y culturales como límites a las políticas públicas: El caso del derecho a la educación en Chile». Derecho del Estado, 34: 237-254. DOI: 10.18601/01229893.n34.11.

Panizza, Francisco (1995). «Human rights in the processes of transition and consolidation of democracy in Latin America». Political Studies, 43: 168-188. DOI: 10.1111/j.1467-9248.1995.tbo1742.x.

Parker, Cristian (2003). «Abstencionismo, juventud y política en el Chile actual». Revista de Estudios Avanzados Inter@ctivos, 2 (4): 1-23.

PNUD, Programa de Naciones Unidas para el Desarrollo (2014). Informe auditoria a la democracia: Más y mejor democracia para un Chile inclusivo. Santiago: Lom.

Reyes, Leonora, Javier CAmpos, Luis Osandón y Carlos MuÑoz (2013). «El profesorado y su rol en la formación de los nuevos ciudadanos: Desfases entre las comprensiones, las actuaciones y las expectativas». Estudios Pedagógicos, 39 (1): 217237. DOI: 10.4067/So718-07052013000100013.

Richard, Pierre Claude (2005). "The right to education and human rights education». Sur, 2 (2): 36-59. DOI: 10.1590/S1806-64452005000100003.

Santisteban, Antoni y Joan Pagés (2008). «La educación democrática de la ciudadanía: Una propuesta conceptual». En Rosa María Ávila y otros (editores), Las competencias profesionales para la enseñanza-aprendizaje de las ciencias sociales ante el reto europeo y la globalización. Bilbao: Asociación Universitaria del Profesorado de Didáctica de las Ciencias Sociales.

Toro, Sergio (2008). «De lo épico a lo cotidiano: Jóvenes y generaciones políticas en Chile». Revista de Ciencia Política, 28 (3): 143-16o. DOI: 10.4067/ So718-090X2008000200006.

Ugarte, Carolina, Charo Repáraz y Concepción Naval (2013). «Participación y abstención de los jóvenes en las elecciones al Parlamento Europeo de 2009: Una respuesta desde la educación cívico-política». Educación XX1, 16 (2): 209-230. DOI: 10.5944/educxx1.2.16.10339.

VALENCIA, Rafael (2010). «El debate en el sistema educativo español: La implantación 
de educación para la ciudadanía». Revista de Derecho, 23 (2): 67-82. DOI: 10.4067/ So718-09502010000200004.

Vilajosana, Josep (2009). «La justificación de la abstención». Revista de Estudios Políticos, 104: 165-18o. Disponible en http://bit.ly/2Avw2zo.

\section{Reconocimiento}

Investigación realizada en el marco del Proyecto de Investigación DI 14-oo98, financiado por la Dirección de Investigación de la Universidad de La Frontera. Proyecto adscrito al Centro de Derechos Humanos de la Universidad de La Frontera.

\section{Sobre los autores}

Leonardo Castillo es máster universitario en Análisis Económico del Derecho, Universidad Complutense, España. Magíster en Política y Gobierno, Flacso. Departamento de Ciencias Jurídicas, Universidad de La Frontera, Chile. Su correo electrónico es leonardo.castillo@ufrontera.cl.

Soledad Morales es magíster en Ciencias Sociales Aplicadas, Universidad de La Frontera, Chile. Escuela de Derecho, Universidad de La Frontera. Su correo electrónico es soledad.morales@ufrontera.cl. 


\title{
REVISTA PEDAGOGÍA UNIVERSITARIA Y DIDÁCTICA DEL DERECHO
}

La Revista Pedagogía Universitaria y Didáctica del Derecho (RPUDD) es una publicación científica semestral que contribuye tanto a la reflexión multidisciplinaria sobre Pedagogía Universitaria y Didáctica del Derecho, para la formación y consolidación de esta área de investigación, como a la difusión de prácticas innovadoras en la enseñanza-aprendizaje del Derecho, considerando el contexto nacional e internacional..

\author{
DIRECTORA \\ María Francisca Elgueta Rosas \\ ASISTENTE EDITORIAL \\ Priscilla Saavedra Medinas \\ SITIO WEB \\ pedagogiaderecho.uchile.cl \\ E-MAIL \\ rpedagogia@derecho.uchile.cl \\ LICENCIA DE ESTE ARTÍ́CULO
}

Creative Commons Atribución Compartir Igual 4.0 Internacional

\author{
9 \\ La edición de textos, el diseño editorial \\ y la conversión a formatos electrónicos de este artículo \\ han estado a cargo de Tipográfica \\ (www.tipografica.cl).
}

